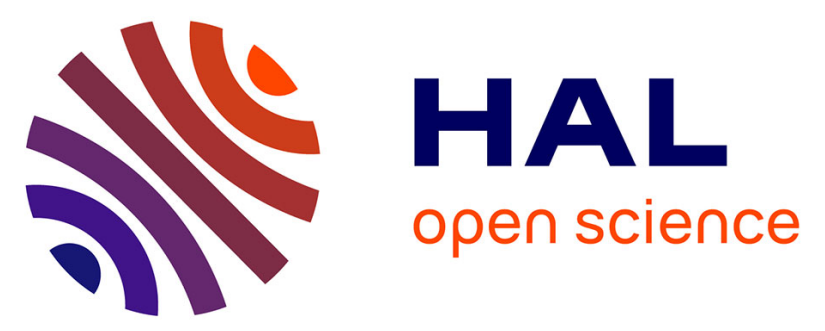

\title{
Linear enamel hypoplasia in large-bodied mammals of Pleistocene northern Vietnam, with a special focus on Pongo
}

Anne-Marie Bacon, Antoine Pierre-Olivier, Thi Mai Huong Nguyen, Kira Westaway, Jian-Xin Zhao, Anh Tuan Nguyen, Philippe Duringer, Jean-Luc Ponche, Canh Dung Sam, Huu Nghia Truong, et al.

\section{To cite this version:}

Anne-Marie Bacon, Antoine Pierre-Olivier, Thi Mai Huong Nguyen, Kira Westaway, Jian-Xin Zhao, et al.. Linear enamel hypoplasia in large-bodied mammals of Pleistocene northern Vietnam, with a special focus on Pongo. Quaternary International, 2020. hal-03021287

\section{HAL Id: hal-03021287 \\ https://hal.science/hal-03021287}

Submitted on 24 Nov 2020

HAL is a multi-disciplinary open access archive for the deposit and dissemination of scientific research documents, whether they are published or not. The documents may come from teaching and research institutions in France or abroad, or from public or private research centers.
L'archive ouverte pluridisciplinaire HAL, est destinée au dépôt et à la diffusion de documents scientifiques de niveau recherche, publiés ou non, émanant des établissements d'enseignement et de recherche français ou étrangers, des laboratoires publics ou privés. 
Linear enamel hypoplasia in large-bodied mammals of Pleistocene northern Vietnam, with a special focus on Pongo

\section{Bacon Anne-Marie}

CNRS FRE 2029 BABEL, Université de Paris, Faculté de chirurgie dentaire, 1 rue Maurice Arnoux, 92120 Montrouge, France.

anne-marie.bacon@parisdescartes.fr

Antoine Pierre-Olivier

Institut des Sciences de l'Évolution de Montpellier, UM, CNRS, IRD, EPHE, CC64, Place

Eugène Bataillon, 34095 Montpellier, France.

pierre-olivier.antoine@umontpellier.fr

Nguyen Thi Mai Huong

Anthropological and palaeoenvironmental Department, Institute of Archaeology, 61, Phan Chu Trinh Street, Hoan Kiem district, Ha Noi, Viet Nam.

maihuong72@gmail.com

\section{Westaway Kira}

'Traps' MQ Luminescence Dating Facility, Dept Earth and Environmental Sciences, Macquarie University, Sydney, NSW 2109 Australia.

kira.westaway@mq.edu.au

Jian-xin Zhao

School of Earth and Environmental Sciences, University of Queensland, Brisbane, Queensland 4072, Australia.

j.zhao@uq.edu.au

Nguyen Anh Tuan

Anthropological and palaeoenvironmental Department, Institute of Archaeology, 61, Phan

Chu Trinh Street, Hoan Kiem district, Ha Noi, Viet Nam.

nguyenanhtuan_bio@yahoo.com.vn

Duringer Philippe

Ecole et Observatoire des Sciences de la Terre, Institut de Physique du Globe de Strasbourg, CNRS, UMR 7516, Université de Strasbourg, 1, rue Blessig, 67084 Strasbourg, France.

duringer@unistra.fr

Ponche Jean-Luc

ICPEES / LIVE / DYLBAS, Institut de Géologie, Université de Strasbourg, 1, rue Blessig, 67084

Strasbourg, France.

ponche@unistra.fr

\section{Sam Canh Dung}

Lang Son museum, 2, Hung Vuong Street, Chi Lang district, Lang Son city, Viet Nam.

samcanhdung@gmail.com

Truong Huu Nghia

Anthropological and palaeoenvironmental Department, Institute of Archaeology, 61, Phan

Chu Trinh Street, Hoan Kiem district, Ha Noi, Viet Nam.

truonghuunghiakch@gmail.com

Tran Thi Minh

Anthropological and palaeoenvironmental Department, Institute of Archaeology, 61, Phan Chu Trinh Street, Hoan Kiem district, Ha Noi, Viet Nam.

tranthiminh86@gmail.com

Pham Thanh Son 
Prehistoric Archaeology Department, Institute of Archaeology, 61, Phan Chu Trinh street, Hoan Kiem district, Ha Noi, Viet Nam.

thanhson9119@gmail.com

\section{Nguyen Thi Kim Thuy}

Anthropological and palaeoenvironmental Department, Institute of Archaeology, 61, Phan

Chu Trinh Street, Hoan Kiem district, Ha Noi, Viet Nam.

thuytien253@yahoo.com

\section{Demeter Fabrice}

Musée de l'Homme, HNS, UMR 7206, 17 Place du Trocadéro, 75116 Paris, France.

Center for GeoGenetics, Øster Voldgade 5-7, 1350 Copenhagen K, Denmark.

demeter@mnhn.fr

\section{Corresponding author}

Bacon Anne-Marie

CNRS FRE 2029 BABEL, Université de Paris, Faculté de chirurgie dentaire, 1 rue Maurice

Arnoux, 92120 Montrouge, France.

anne-marie.bacon@parisdescartes.fr

tél: +33 (0)6.75.55.16.86

\section{Abstract}

The Coc Muoi fauna provides a good example of the type of tropical mammalian communities that existed in northern Vietnam during the late Middle Pleistocene. The first results of the analysis of hypoplasia indicated that rhinoceroses and wild cattle were exposed to multiple physiological and psychological stress events specific to age [Bacon et al., 2018. A rhinocerotid-dominated megafauna at the MIS6-5 transition: The late Middle Pleistocene Coc Muoi assemblage, Lang Son province, Vietnam. Quat. Sci. Rev. 186, 123141].

In this paper, we aim to supplement the study of hypoplasia in the orangutans (Pongo) from Coc Muoi and, more widely, from different Pleistocene faunas. To address this issue, we conducted a macroscopic analysis of linear enamel hypoplasia [LEH] on Pongo from three collections: Coc Muoi (148 - 117 ka), Duoi U'Oi (70 - 60 ka), and Tham Khuyen (>475 ka).

Such comparative analysis based on isolated teeth is constrained by numerous biases including: the small datasets; the differential representation of tooth types; the difficulty in distinguishing first from second molars; the small number of individuals [MNI]; the differential representation of males versus females. The data analysis has been divided into two parts: (1) an analysis of the frequency and expression of LEH on incisors, premolars, and molars (three sites), and (2) an analysis of the frequency and expression of LEH on a set of canines (Tham Khuyen). We used a reference sample composed of 17 adult and 10 immature Pongo individuals to determine the age range of fossil Pongo individuals, at the time of the defects.

Results show that hypoplasia was a common phenomenon in Pleistocene Pongo: two individuals at Coc Muoi; 2 out of 3 individuals at Duoi U'Oi; and 4 out of 6 individuals at Tham Khuyen. They experienced multiple stresses between $\sim 2$ and 5 years of age, a period of great vulnerability for immature individuals. The occurrence of accentuated lines of hypoplasia on canine crowns of Tham Khuyen suggests a greater intensity of the stressor, in a time range consistent with the long dietary and behavioral transition of the weaning. 
In terms of paleoecology, Pleistocene orangutans from the Asian mainland could survive in different environmental conditions than those they occupy today. Various sources (archaeozoology, geological context, and ecology of wild populations), suggest that they might have been larger apes than extant orangutans, living in limestone forests on hills and tower karsts.

Key-words: Orangutans, large-bodied Ungulates, Life-history, Weaning, Southeast Asia.

\section{Introduction}

The Coc Muoi fauna documents a terrestrial ecosystem supporting megaherbivores in northern Vietnam, during the late Middle Pleistocene. The mammal assemblage has been constrained by age estimates obtained from the dating of fossiliferous breccia deposition in the cave site (Optically stimulated luminescence [OSL] and post-IR IR-stimulated luminescence [pIR-IRSL]), which produce an age range within a $1 \sigma$ confidence interval of 148 - $117 \mathrm{ka}$ (Bacon et al., 2018a). The faunal analysis of the assemblage revealed the exceptional predominance of rhinoceroses (especially Rhinoceros sondaicus) amongst other large-bodied mammals (tapirs, wild cattle, elephants and stegodons). At that time, Indochinese mammalian guilds were also shaped by the presence of various herbivores and omnivores (muntjacs, sambar deer, medium-sized cervids, medium-sized bovids, porcupines, wild pigs, pandas, bears, macaques, and orangutans), and carnivores (tigers, leopards, and dholes), as the composition of the Coc Muoi fauna shows. In the first analysis of the fauna (Bacon et al., 2018a), we conducted a study of the prevalence of linear enamel hypoplasia [LEH] on the teeth of rhinocerotids (R. sondaicus, $R$. cf. unicornis, Dicerorhinus sumatrensis), bovids (Bos cf. sauveli), and tapirids (Tapirus indicus, Megatapirus augustus), to assess their health status during the first years of growth, in comparison with the prevalence estimated on the same taxa from some other Late Pleistocene Indochinese faunas (Tam Hang and Nam Lot in Laos; and Duoi U'Oi in Vietnam).

Dental enamel hypoplasias are deficiencies in enamel thickness resulting from physiological perturbations (stress) during the secretory phase of amelogenesis (Goodman and Rose, 1990: p.59). It is a common phenomenon in natural populations of large mammals. Large-bodied mammals are characterized by slow life-histories and a sensitivity to environmental stressors and, in these animals, hypoplasia is mostly caused by undernutrition and disease. Hypoplasia is particularly exacerbated when physiological stresses occur during key-events of development and growth (Hillson and Bond, 1997; Hillson, 2005; Dobney and Ervynck, 1998, 2000; Dirks et al., 2002, 2010; Niven et al., 2004; Franz-Odendaal, 2004; Skinner et al., 2012; Skinner and Skinner, 2017). In relation to large ungulates (rhinocerotids and bovids) of the Indochinese fossil sites, the results showed that hypoplasia is associated with physiological stresses specific to perinatal events, weaning, abandonment of calf and sexual maturity. In tapirids, no hypoplastic defects were observed (Bacon et al., 2018a). The prevalence and expression of hypoplasia remain however widely underexplored in fossil mammals from the region.

Like these large-bodied ungulates, orangutans (Pongo) have a particularly long period of immaturity in conjunction with long periods of crown formation (Guatelli-Steinberg, 2001). They are, together with gorillas, the most dimorphic apes in terms of body mass, with the mean weight of males ( $78 \mathrm{~kg}$ ) more than twice that of females ( $35 \mathrm{~kg}$ ) (Smith and Jungers, 1997). In the wild, infants remain dependent on their mothers for at least 6 years, and they reach sexual maturity between 11 and 15 years of age. Pongo species are distinguished particularly by a gradual weaning process and the late full independence of juveniles, which 
make them vulnerable throughout their period of development (Galdikas and Wood, 1990; Delgado and van Schaik, 2000; Jablonski et al., 2000; Knott, 2001; Wich et al., 2004, 2009; van Noordwijk and van Schaik, 2005).

Studies show that, among wild populations of great apes, there is a great interspecific variability, but it should be noted that the analyses are based on different sample sizes, and different methods of recording LEH-affected individuals (Guatelli-Steinberg et al., 2012; Table 1). Orangutans (Pongo abelii and $P$. pygmaeus) have the highest prevalence of hypoplasia, with 79 to $100 \%$ of individuals (Guatelli-Steinberg, 2000; Hannibal and GuatelliSteinberg, 2005; Guatelli-Steinberg et al., 2012). Proportions vary significantly between Gorilla species, with 5.3 to $11 \%$ (G. beringei), 39 to $95 \%$ (G. gorilla), 75\% (G. grauei), and between Pan species but to a lesser extent, with $\sim 69.7-95.7 \%$ (P. troglodytes) and 95.7 - 98 \% (P. paniscus) (Skinner, 1986a; Eckhardt, 1992; Stottlemire, 1998; GuatelliSteinberg, 2000; Hürner and Vercauteren, 2003; Hannibal and Guatelli-Steinberg, 2005; Guatelli-Steinberg et al., 2012). All three taxa show the repetitive occurrence of LEH marks on incisors and canines, suggesting repeated stress events, but they differ in the mean number of recorded episodes, with ranges from 4.5 - 7.4 in Pongo, 3.1 - 4.7 in Pan, and 0.1 5.4 in Gorilla (Guatelli-Steinberg et al., 2012). An array of factors have been explored to attempt to explain the significance of these differences between great apes: biological factors such as enamel formation time, the level of abrasion of the surface of dental crowns, the angles between striae of Retzius and the enamel surface (Hannibal and GuatelliSteinberg, 2005; Guatelli-Steinberg et al., 2012), or ecological factors related to the environmental context such as habitat, climate and seasonality, or again related to food availability, particularly the abundance of fruit (versus leaves) in ape diets. Overall, studies indicate that linear enamel hypoplasia is most likely influenced by a complex combination of factors (Dean, 2010), and that there is evidently a great variability in the way individuals feel stress.

In relation to wild populations of orangutans, it has been proposed that marked repetitive sequences of linear hypoplasia might be explained by a significant stressor, with an average periodicity of six months (or a multiple of six months), lasting 6 - 8 weeks. The nature of this stressor, however, remains unknown, although it has been suggested that seasonal changes are deeply involved (Skinner, 2000; Skinner and Hopwood, 2004; Skinner and Skinner, 2017). Temperature and humidity greatly influence the degree of virulence of parasites responsible for diseases and malnutrition in immature individuals, but some other factors may be important: the density of animals, which increases infection rates (Foitová et al., 2009), genetics (Goodman and Rose, 1990; Miles and Grigson, 2003), and annual or supra-annual variation in fruit cycling (Knott, 1998).

In this paper, we present the results of a macroscopic analysis of enamel hypoplastic defects in three fossil collections of Pongo teeth: the late Middle Pleistocene Coc Muoi Pongo cf. devosi (148 - $117 \mathrm{ka}$; Bacon et al., 2018a); the Late Pleistocene Duoi U'Oi $P$. pygmaeus (70 - 60 ka; Bacon et al., 2008, 2015, 2018b). The Middle Pleistocene Tham Khuyen series of isolated teeth have been allocated to various species, $P$. pygmaeus (Cuong, 1985), P. pygmaeus and P. hooijeri (Schwartz et al., 1995), or P. weidenreichi (Harrison et al., 2014), the age of which is however not precisely known (>475 ka; Ciochon et al., 1996). Despite multiple biases due to the nature of the fossil collections, our analysis seeks to test whether the Pleistocene Pongo experienced a level of developmental stress comparable to that of infants and juveniles (weaned immature individuals) from extant orangutan populations. Finally, the analysis of hypoplasia in the Coc Muoi large-bodied mammals, 
allows us to highlight the health status and level of stress of a late Middle Pleistocene fauna in a tropical ecosystem.

\section{Previous results on Coc Muoi and Duoi U'Oi large-bodied ungulates}

\subsection{Dating and faunal context}

Both faunal assemblages, almost essentially composed of isolated teeth of medium- to large-sized mammals, were recovered from karstic breccias in cave sites in northern Vietnam (Figure 1SI). Their analysis revealed that they share comparable taphonomic pathways, due to the action of biotic (bone accumulator, either rodents or carnivores) and abiotic (water flows) agents, through processes of deposition (Bacon et al., 2015; 2018a).

Duoi U'Oi yielded 871 teeth (NISP), representing a fully modern fauna (Bacon et al., 2008). The estimated age of the fauna (70-60 ka) is based on U-series dating of the calcitic floor (66 $\pm 3 \mathrm{ka}$ ) that crosses the fossiliferous breccia, and luminescence dating of the underlying sandy and silty clay unit (Bacon et al., 2015). Rhinocerotid teeth have been attributed to three species, Rhinoceros sondaicus, $R$. unicornis and Dicerorhinus sumatrensis.

Coc Muoi yielded 1323 isolated teeth (NISP) (Bacon et al., 2018a). The fauna is a mix of modern and archaic taxa, characteristic of the mammalian communities of the Middle Pleistocene to the first half of the Late Pleistocene in the region. The dating of the cave sediments (OSL and pIR-IRSL) indicate a potential age range of 148 - $117 \mathrm{ka}$. Rhinocerotid teeth have been attributed to the same three Asian species, whereas the large bovid teeth have been tentatively assigned to Bos cf. sauveli, the kouprey.

\subsection{LEH data in rhinocerotids and bovids}

In this first macroscopic analysis of ungulates, we described the frequency and location of linear marks of hypoplasia on deciduous and permanent teeth. In Coc Muoi rhinocerotids, $73.1 \%$ of teeth showed no signs of LEH, whereas the percentage of Duoi U'Oi teeth was much higher $(90.3 \%)$, with a notable difference in the numbers of teeth between samples (264 versus 52, respectively) (Table 1). The analyses had highlighted the small percentage of milk molars (4/144, $2.7 \%$ ) affected by linear hypoplasia in the Coc Muoi sample with respect to permanent teeth, and only 2 out of 5 milk molars in the Duoi U'Oi assemblage.

Enamel hypoplasia in the Coc Muoi rhinocerotids is most expressed on the last premolars (P4 and p4; 11/30, 36.6 \%) and molars (M3 and m3; 27/64, 42.1 \%) (Bacon et al., 2018a), i.e. the last erupting teeth. These teeth recorded between one to four LEH episodes ( $v s$ one to two LEH episodes for Duoi U'Oi but with a smaller dataset) (Table 1).

In Coc Muoi bovids, $84 \%$ of the teeth showed no signs of LEH (Table 1). No hypoplasia has been observed on the four milk teeth (4 out of 69) (Bacon et al., 2018a). Among the 65 permanent teeth, eleven molars recorded one $(10 / 11,14.4 \%$,) to two LEH $(1 / 11,1.4 \%)$ episodes (Table 1), with proportions of $6.6 \%(1 / 15)$ of $m 1,31.2 \%(5 / 16)$ of $m 2$, and $5.5 \%$ (5/9) of m3 (Bacon et al., 2018a).

Considering the chronology of tooth development and the location of the LEH defect on the surface of the crowns, it was possible to deduce within what age range the stress event occurred for each individual (Bacon et al., 2018a). In the studied ungulates, crown formation is a process starting in utero (deciduous dentition and the first permanent teeth begin to form) and continuing around and after birth (permanent dentition). In rhinoceroses, P4/p4 and $\mathrm{M} 3 / \mathrm{m} 3$ are the last teeth to form, erupting at around $\sim 7-9$ years old in Ceratotherium simum and Diceros bicornis (Goddard, 1970; Hillman-Smith et al., 1986), whereas in large bovids, all three premolars and $\mathrm{M} 3 / \mathrm{m} 3$ are the last teeth to form, erupting after circa 2 
years of age (Bison bison; Niven et al., 2004) (Table 2). Results highlighted perinatal events and the interval coinciding with abandonment of calf and sexual maturity in rhinocerotids, particularly at Coc Muoi ( $4-6$ years; 10 out of 25 individuals), as physiologically stressful periods. Bovids were exposed to a relatively high degree of undernutrition and disease during weaning ( $\sim 9$ months), and when they reached sexual maturity ( 2 years).

\section{LEH data in recent and fossil orangutans}

\subsection{Material}

We used a sample of seventeen adult individuals (twelve males, four females, and one of unknown sex), to assess the prevalence of hypoplasia and its range of expression on the permanent teeth of recent orangutans. Ten additional immature individuals (four males, one female, and five of unknown sex) with full deciduous dentition and erupted $\mathrm{M} 1 / \mathrm{m} 1$ were also selected to evaluate the prevalence of defects on deciduous teeth and the first permanent molars. Within this overall sample, sixteen adult and eight immature individuals had been caught in the wild and spent the rest of their lives in the zoo, while three were born at the zoo (Ménagerie du Jardin des Plantes, Paris). Only three specimens come from the island of Borneo, and can therefore be attributed to Pongo pygmaeus (Brandon-Jones et al., 2004), but their populations of origin are unknown. The island origin of the other 21 specimens is unknown. Therefore, the recent Pongo collection used here does not reflect a natural population. The collection is housed in the Laboratoire Mammifères et Oiseaux, Anatomie comparée of the Muséum national d'Histoire naturelle, in Paris (Table 1SI).

Due to the poor preservation of some fossil teeth, damaged or heavily worn, we selected 20 out of 25 permanent teeth in the Coc Muoi assemblage, and 60 out of 66 permanent teeth in the Tham Khuyen assemblage. The Duoi U'Oi sample consists of 30 permanent teeth and 2 milk teeth (out of 34 teeth) (Table 3). The orangutans from Coc Muoi have been assigned to Pongo cf. devosi (Bacon et al., 2018a), those from Duoi U'Oi to P. pygmaeus (Bacon et al., 2008), whereas those from Tham Khuyen are now considered to belong to $P$. weidenreichi (Harrison et al., 2014). However, tooth sizes between the three fossil samples show significant overlap (Table 2SI). Moreover, as mentioned by Harrison et al. (2014), taxonomic assignment of species based on isolated teeth must be cautiously considered. The data were collected in Vietnam on the original specimens at the Lang Son museum, Lang Son province (Coc Muoi), and at the Institute of Archaeology in Hanoi (Tham Khuyen and Duoi U'Oi).

\subsection{Method}

Given the precious nature of fossils, histological analyses (O'Hara, 2017; McGrath et al., 2018) were excluded. Moreover, some teeth presented worn crown surfaces with smoothened incremental marks, preventing the counting of perikymata. Thus, to address this issue, we conducted a macroscopic analysis of enamel hypoplasia. Furthermore, we deliberately limited our data collection to linear enamel hypoplasia [LEH], and ignored all other defects randomly distributed on crown surfaces. Some teeth were quite difficult to analyze due to the cratering of the enamel, especially those from Tham Khuyen and Coc Muoi. The causes of these marks (accidents, feeding behavior, damages due to transport, deposition and burial in the karsts, and/or recovery) could not however be established.

Such study of isolated teeth inevitably introduces important limitations and constraints: the different compositions of the three assemblages regarding tooth types, the fact that some molars cannot be assigned to a specific position on dental rows, and the fact that a set of isolated teeth can comprise several teeth belonging to a single individual. Furthermore, 
the calculation of the minimum number of individuals [MNI], based on the most frequent type of tooth, reveals the small datasets: $\mathrm{MNI}=2$ at Coc Muoi (4 upper right $\mathrm{M} 1 / \mathrm{M} 2$ ), $\mathrm{MNI}=$ 3 at Duoi U'Oi (3 lower right p3), and MNI = 6 at Tham Khuyen ( 6 upper right P3).

LEH expression has been recorded from the original specimens, either modern or fossil, in the museums, with the naked eye. The scoring process has then been repeated in the laboratory using the images of each specimen, under low magnification (x10) until replicability was attained. Data were collected on the labial side of teeth of modern and fossil specimens by a single observer (AMB) to minimize inter-observer variability. As Figure 1 shows, LEH has multiple expressions. However, we did not observe in both fossil and recent samples, pit-type defects scattered over the surface of tooth crowns, as described by Witzel et al., (2006; Fig.1C). The two criteria chosen to describe the morphology are those commonly used for mammals (Hillson and Bond, 1997; Hillson, 2005): (1) a line of pits, thin or wide, visible or partly visible on the contour of the crown; (2) a furrow, thin or wide, visible or partly visible on the contour of the crown. The pit-form defects appear when clusters of ameloblasts stop forming enamel matrix, whereas ameloblasts in between the disrupted clusters continue to produce normal enamel matrix (Hillson and Bond, 1997). The line displays either small and shallow pits, or deep pits located in a marked groove (Figure $1 \mathrm{~A}-\mathrm{B})$. In the furrow-form defects, ameloblasts ceased simultaneously matrix production, giving them a more regular aspect (Figure 1C-D). We considered only the lines and furrows that can be matched on teeth forming at the same time, and which have similar systemic causes (Hillson and Bond, 1997) (Figure 2). The criteria used for the location of the defects with regards to crown height are those used in previous analyses (Bacon et al., 2018a): (1) basal third; (2) middle third, and (3) occlusal third, estimated between the cervix and the tip of cusps.

Table 3 shows a clear discrepancy in the number of canines between samples. This is why we have divided the data analysis into two parts: (1) the first analysis of hypoplasia on the crown surfaces of the incisors, premolars, and molars from the three sites (Coc Muoi, Duoi U'Oi, and Tham Khuyen), and (2) the second analysis of hypoplasia on the set of canines from Tham Khyuen.

In order to estimate the biological age range of fossil individuals on isolated teeth at the time of physiological defects, we used a reference Table based on our observations of LEH on the seventeen skulls of recent adult Pongo individuals (Table 4). Incisors, canines and premolars develop overall concurrently, with however a great variability in the sequence and the period of development, initiation of crown mineralization, crown completion time, root formation, and eruption time (Swindler, 1985; Dean and Wood, 1981; Dean and Beynon, 1991; Beynon et al. 1991; Winkler et al., 1991, 1996; Schwartz and Dean, 2001; Kelley and Schwartz, 2010; Smith, 2016). In contrast, the three molars develop separately with little temporal overlap in crown formation time (the first molars $M 1 / \mathrm{m} 1$ are the first teeth to form around birth; the initiation of calcification of $\mathrm{M} 2 / \mathrm{m} 2$ occurs before - or at least simultaneous - the end of the crown completion of $\mathrm{M} 1 / \mathrm{m} 1$; likewise, the initiation of calcification of $\mathrm{M} 3 / \mathrm{m} 3$ occurs before - or at least simultaneous - the end of the crown completion of $\mathrm{M} 2 / \mathrm{m} 2$ ) (Figure $2 \mathrm{SI}$ ). Therefore, we used crown formation time span of the permanent molars and defined three age groups: birth - 3 years (M1/m1), 2 - 5 years $(\mathrm{M} 2 / \mathrm{m} 2)$, and $\sim 4-8$ years $(\mathrm{M} 3 / \mathrm{m} 3)$ (Figure $2 \mathrm{SI})$. Given the large variability observed in extant individuals, the intervals used here are large enough to encompass mean estimates of molar crown formation times in Asian apes (Dean and Wood, 1981; Anemone et al., 1991; Kuydendall, 1996; Winkler et al., 1996; Reid et al., 1998; Smith, 2016; Dean, 2010). 
In the second analysis, considering the differential representation of tooth types in sites (Table 3), only seven lower canines of Tham Khuyen could be addressed in a comparative study with those of recent Pongo. Canines have the longest crown formation time of all tooth classes, with crown mineralization beginning shortly after birth until around ten years of age (Beynon et al., 1991; Dean et al., 1993; Winkler et al., 1996; Schwartz and Dean, 2001). In Pongo, like in other highly dimorphic large-bodied apes (Gorilla), the difference in canine crown height between males and females (Kelley, 1995; Waddle et al., 1995), is due to distinct growth durations. With a range of 7.2 - 9.6 years (8.83 years on average), males complete enamel formation later, after a longer time than females ( $4.5-6.3$ years; 5.47 years on average; Schwartz and Dean, 2001). Therefore, this long duration of crown formation combined with a high susceptibility to record physiological stresses (Goodman and Armelagos, 1985; Skinner, 1986a), makes canines display the largest number of LEH episodes of all types of teeth. Moreover, in males, canines record hypoplastic episodes when enamel formation of the $\mathrm{M} 3 / \mathrm{m} 3$ has ceased and can then reveal additional information on the stress events that followed.

Each Tham Khuyen canine has been sexed based on measurements of crown height taken in specimens of recent Pongo pygmaeus (P. p. pygmaeus and P. p. abelii): males (range, 17.2 - $28.2 \mathrm{~mm}, \mathrm{n}=20$ ) and females (range, 14.1 - $23.1 \mathrm{~mm}, \mathrm{n}=20$ ) (Waddle et al., 1995). The Tham Khuyen collection is composed of six canines from males, and one canine from a female. Taking into account that two canines (TK138 and TK157) could belong to a single individual, we obtained a MNI of 4 (three males and one female).

In addition to the LEH frequency and expression, we used some parameters defined by Skinner and Hopwood (2004), such as the relative spacing between two adjacent episodes of LEH (the interval measured between the end of one LEH episode and the beginning of the next), the timing of the apparent onset of stress (the distance from the location of the first LEH to the cervix), and the duration of stress inferred from the span between the first and the last episode of LEH), all standardized against crown height. All the parameters used here have been defined using spatial measurements, and not the count of perikymata, for a comparable precision, and thus an accurate comparison. A Mitutoyo digital caliper was used to measure distances on canine crowns.

In the present intrageneric analysis which includes past and present Pongo species, we made the assumption that the enamel of all specimens shares common intrinsic characteristics. These include histological properties, the susceptibility of teeth to hypoplasia, the spacing of perikymata over the height of the crown, striae angles, the crown formation times, and the enamel thickness (see Hannibal and Guatelli-Steinberg, 2005, for further details on the intergeneric variability of these factors in great apes).

\section{Results}

4.1. LEH prevalence on Pongo milk teeth

The observation on recent immature individuals $(N=10)$ having complete deciduous dentition and permanent $\mathrm{M} 1 / \mathrm{m} 1$, shows the low prevalence of hypoplasia on milk teeth. Only one (out of 10 individuals) has affected milk dentition. In this individual, one LEH defect is located on the basal third of $\mathrm{M} 1 / \mathrm{m} 1$, and another one is visible as a thin depression of enamel on the mid-portion of deciduous canines (in a second individual, one defect is also located on the basal third of $\mathrm{M} 1 / \mathrm{m} 1$, and there is no observable LEH on milk teeth). We did not observe localized hypoplasia in this Pongo sample, as described by several authors (Skinner, 1986b; Lukacs, 1999; Skinner and Newell, 2003). 
Only the Duoi U'Oi collection contains two milk teeth, one upper central incisor and one lower canine $(\mathrm{MNI}=1)$, both without LEH or localized hypoplasia.

\subsection{LEH prevalence on Pongo permanent teeth}

In our recent Pongo sample ( $N=17), 94.1 \%$ of adult individuals $(16 / 17)$ were affected by hypoplasia (individuals showing at least one LEH episode). Interestingly, the only specimen which shows no LEH marks is the individual born in the zoo.

In the fossil samples, Coc Muoi has the highest percentage of teeth with LEH marks (70 \%), Duoi U'Oi the lowest (43.3\%), and Tham Khuyen is in between (46.6\%) (Table 5).

At Coc Muoi (MNI =2), both individuals were affected by hypoplasia, 2 out of 3 individuals at Duoi U'Oi, and 4 out of 6 individuals at Tham Khuyen.

\subsection{Number of LEH episodes (incisors, premolars, and molars)}

In recent Pongo, results indicate that $29.4 \%$ of individuals (5/17) experienced one LEH episode, $23.5 \%$ (4/17) two LEH episodes, and $29.4 \%$ three LEH episodes. Cases with four or five LEH episodes were few (2/17) (Table 6).

Using the three tooth types (incisors, premolars, and molars), results show that the Coc Muoi teeth recorded one (47.3\%) to two (26.3\%) LEH episodes, one (9.4 \%) up to three $(9.4$ $\%)$ at Tham Khuyen, and one (27.5 \%) up to four (3.4\%) at Duoi U'Oi (Table 6). If we consider overall fossil data, teeth with more than three LEH episodes are few, following the pattern observed in the recent Pongo sample.

\subsection{Number of LEH episodes per period}

Table 7 illustrates the number of LEH episodes observed in recent Pongo $(\mathrm{N}=17)$, using the three periods defined on crown formation time of the permanent molars. Most individuals (16/17) show no LEH episode between birth and $\sim 3$ years of age (i.e. strong enough to have been recorded during crown formation of the first molars, and visible under low magnification). Only one specimen displays LEH on $\mathrm{M} 1 / \mathrm{m} 1$ (a faint furrow only visible on the lingual side of crown in one female individual). The observation of the additional immature individuals $(N=10)$ confirmed the low prevalence of hypoplasia in the first three years of life with only 2 out of 10 individuals showing a line of hypoplasia on the permanent first molars. All other LEH episodes occurred in the subsequent periods, i.e. during crown formation times of the second and third molars, approximately between $\sim 2$ and 8 years of age, with great variability between individuals.

Table 8 illustrates the number of LEH episodes (range and mean) per period in recent Pongo (only individuals showing at least one episode have been selected here; $N=16$ ). Results indicate that the period $\sim 2$ - 5 years was critical for immature individuals. Males had two LEH episodes on average (8 out of 11 individuals), and females 1.5 episodes (all 4 individuals). The frequency of episodes decreased in the $\sim 4-8$ years period. Males had 1.5 LEH episodes on average ( 6 out of 11 individuals), and females only one episode ( 2 out of 4 individuals). The amount of data is however insufficient for a statistical analysis of the prevalence in males versus females. When considering the overall sample, the $\sim 2-5$ years period evidently appears to be the period recording the greatest number of episodes with 1.92 on average (13/16 individuals), compared to 1.37 for the following period $\sim 4-8$ years (8/16 individuals). 
Table 9 indicates the number and range of LEH episodes observed on fossil teeth in each period (see Table 4SI for details). Using teeth that can be placed easily on dental rows (incisors, premolars, and third molars), the results show a greater record of LEH episodes during the periods $\sim 2-5$ years (up to 3 ) and $\sim 4-8$ years (up to 2 ), than during the first three years of life, like in their modern counterparts.

Although based on samples of small size, data also suggest that the $\sim 2-5$ years interval was a critical period for immatures, with one individual at Coc Muoi, and two individuals at Duoi U'Oi and Tham Khuyen. Only Tham Khuyen shows however more affected individuals (all four individuals) in the $\sim 4-8$ years period, than is in the previous period ( $2-5$ years) (two individuals), in contrast to what is observed in recent Pongo. But the results are most likely biased due to the greater number of identified $\mathrm{M} 3 / \mathrm{m} 3$ in this collection (Table $4 \mathrm{SI}$ ).

In Table 10, we considered two distinct intervals, $\sim 0$ - 5 years of age (in which we gathered incisors, premolars and all undistinguished first and second molars), and $\sim 4-8$ years (third molars) (Table 4SI). The results support a greater record of LEH episodes before $\sim 5$ years (up to 4 at Duoi U'Oi), than between $\sim 4-8$ years (up to 2 at Coc Muoi and Tham Khuyen). Results also indicate, as previously noted, a relatively greater number of affected individuals in the last period ( $\sim-8$ years) at Tham Khuyen. In this site, three individuals (out of the 4 impacted) suffered stresses over the two periods.

\subsection{Type of defects}

Assessment of the type of the defects (furrow vs line of pits) in our recent Pongo sample reveals that furrows are the most frequent expression of hypoplasia, in all teeth analyzed (incisors, premolars, and molars: 62.5 to $100 \%$ of individuals), compared to lines of pits with 11.1 to $25 \%$ of individuals (Table 11). Contrary to incisors and premolars, molars rarely exhibit both types of hypoplasia (8.3\%).

Four individuals exhibit a line of small and shallow pits visible on one or few tooth types, while the same stress event generated a furrow on adjacent teeth, most likely due to different susceptibility to developmental hypoplasia between tooth types (Table 5SI). In other three individuals, the line which has the appearance of a groove with deep pits can be matched on several or all teeth, that suggests a greater severity of the stressor (Figure 1B).

The results also highlight that among the various tooth types, the P3/p3 are the most frequently impacted (15 out of 16 individuals, $93.7 \%$; Table $5 \mathrm{SI}$ ). We observed on jaws of recent Pongo, that the lower p3 is more likely to display LEH with sometimes deep horizontal troughs that follow lines of hypoplasia, visible on the labial side of the crowns (Figure 1A). These deep troughs seem to be due to a greater fragility of enamel in areas already affected by hypoplasia, a phenomenon most likely accentuated by the position of the tooth on the arcade, its particular labial profile and elongated shape.

Fossil data indicate the predominance of furrows as the commonest type of hypoplasia: all teeth at Duoi U'Oi; 13 out of 14 teeth (92.8\%) at Coc Muoi; 20 out of 21 teeth (95.2\%) at Tham Khuyen) (Table 6SI). One out of the 2 individuals at Coc Muoi displays one line with small and shallow pits on a $\mathrm{M} 1 / \mathrm{M} 2$, and 1 out of the 4 individuals at Tham Khuyen shows two lines of small pits on a lower i1. We did not observe any fossil tooth with both lines of pits and furrows.

\subsection{Distribution of $L E H$ episodes over canine crowns}

In the comparison between the Tham Khuyen lower canines and those of recent Pongo

(Figure 3), using three parameters (relative spacing between two adjacent episodes, timing 
of apparent onset of stress, and duration of stress), the Tham Khuyen data fall within ranges of variability observed in two recent Pongo samples (Table 7SI).

It is also the case for the number of LEH episodes visible throughout the crown height. Results in Table 12 show that this number in the Tham Khuyen sample is close to that observed in recent Pongo, with a range of $1-10$, and a mean of 6.4.

According to the median (Table 12), the value obtained for Tham Khuyen is high $(x=8)$, and close to that of recent $P$. abelii $(n=7)$ (data of Guatelli-Steinberg et al. 2012). Results are most likely biased due to a greater number of male individuals (vs females) in both samples, 3 males and one female at Tham Khuyen, and 7 males and 2 females in the $P$. abelii population.

\subsection{Location, type and age range estimate of the most accentuated LEH episode} on canines

The assessment of the pattern of LEH expression on canines shows that furrows are more common than line of pits: only 2 out of 9 affected individuals exhibit one line of pits (vs 3 to 8 furrows) in our recent Pongo sample, and 2 out of 4 individuals exhibit two lines of pits in Tham Khuyen (vs 1 to 10 furrows).

In order to identify a specific stress event during the development of immature individuals in recent and fossil samples, we assessed the location of the most accentuated linear marks (either furrow or line of pits) visible on the labial surface of the canines, and estimated the age range of individuals based on crown deciles from Skinner and Skinner (2017) (Table 13).

In recent Pongo, 3 out of 9 individuals have similar furrows over the crown height. In the other six individuals, results show that the expression of the most accentuated LEH episode can vary (one wide line of pits, one wide furrow, two close furrows). Among these six individuals, five present a defect which occurred when around two-thirds of the crowns were formed $(0.45-0.23)$. The corresponding age range can be estimated for the males between 4.84 and 7.25 years, and for the female between 3.45 and 4.77 years (Skinner and Skinner, 2017) (Table 13). The last individual was the only one showing an accentuated wide line of pits $(0.66-0.60)$ that developed early during crown formation (Figure $1 \mathrm{~A}$ ), broadly before 4 years of age.

The observation of two canines from Tham Khuyen belonging to two male individuals, shows that the most accentuated defects were recorded when more than two-thirds of crowns were formed $(0.30-0.17)$, corresponding to a biological age range of $6.46-8.09$ years (Table 13). Furthermore, two canines (TK138 and TK157) which could belong to one male individual, display a large zone of disturbed enamel, deep enough to have possibly involved a defect of the underlying dentine (which cannot be ascertained here without microCT- scan) (Figure 3C). A comparable depression-type hypoplasia has been also observed in pigs (Dobney and Ervynck, 1998; Witzel et al., 2006). It has also the characteristics of "coronal waisting" described in a chimpanzee population (Skinner et al., 2012): macroscopic constriction located on the mid-canine crown, well visible on the labial side. On one canine (TK138), the width of the depression could be estimated in the range $\sim 0.20-0.48$, that corresponds broadly to a developmental stress that lasted between 4.84 and 7.25 years (Table 13 ).

\section{Discussion}

5.1. Hypoplasia and life history 
As shown in several publications (Guatelli-Steinberg, 2000; Skinner and Hopwood, 2004; Hannibal and Guatelli-Steinberg, 2005; Guatelli-Steinberg et al., 2012), LEH is a common phenomenon in extant Pongo species (94.1\% of individuals in our reference sample, $100 \%$ when excluding the zoo-born individual). Although based on small datasets, results on incisors, premolars, and molars show that LEH frequencies have different distributions in each period of development: rare episodes from birth to $\sim 3$ years of age, frequent episodes from $\sim 2$ to 5 years, and comparatively fewer episodes from $\sim 4$ to 8 years. Our observations on the seven tooth types match those obtained on lower incisors and canines, all of which show that a specific period during the development of young individuals contains the greatest number of LEH episodes. The period corresponds to the formation of lateral enamel in the mid section of canine crowns (Skinner and Hopwood, 2004; Guatelli-Steinberg et al., 2012). Regarding fossil Pongo, despite the small datasets, the present analysis suggests that hypoplasia might also have been frequent in past populations, with the two Coc Muoi individuals affected, 2 out of 3 individuals at Duoi U'Oi, and 4 out of 6 individuals at Tham Khuyen.

With regard to the morphology of LEH defects, it seems that both recent and fossil samples have a comparable pattern, with furrows more frequent than line of pits. Furrows and linear pits have similar systemic causes, and are associated with stresses due to undernutrition and disease (Goodman and Rose, 1990; Hillson and Bond, 1997) (differently, scattered of pits over the surface of tooth crowns are associated with postnatal deficiencies of vitamins A and D, and of calcium; Lovell and Whyte, 1999; Witzel et al., 2006).

The distribution of LEH episodes in fossil Pongo also follows a comparable pattern to that of the modern species. A combination of factors might explain the low frequencies of hypoplasia in the period "birth - 3 years": first, the small number of involved teeth and the fact that teeth are less likely to display LEH. With regard to incisors, only the appositional zone of crowns is concerned (Table 3SI). In this zone, enamel layers do not appear on the surface and, therefore, don't show evidence of hypoplasia (Hillson and Bond, 1997). The first molars, which begin to form around birth, is also few affected by hypoplasia, most likely due to the low susceptibility to record LEH events (3.4 - 4.8\%, Hannibal and Guatelli-Steinberg, 2005; $6.2 \%$ in our reference Pongo sample, Table 5SI). Immature individuals also have a particular immunity against stressors, obtained from the mother by the nursing, as previously noted by Skinner and Hopwood (2004) who estimated the timing of the onset of stress in apes at around 2.6 years of age. The first three years of life constitute the period of most frequent body contacts between mother and offspring. During the first three months, infants are always in contact with the mother (100\% of the time). This percentage decreases continuously to reach $50 \%$ ca. 2 years of age, and $16 \%$ ca. 2.5 years of age (van Noordwijk and van Schaik, 2005; van Noordwijk et al., 2009; van Adrichem et al., 2006). During the first stage of their lives, young orangutans keep this proximity with their mothers during most activities (feeding, transportation, resting, nesting, etc.), and are less confronted to disturbances due to fluctuations in fruit availability since they feed from their mother's milk, or are less confronted to infections due to parasites since they still have few contacts with the vegetation.

The following period, from around $\sim 2$ to $\sim 5$ years of age, is obviously a period of vulnerability for immature individuals, as results obtained on our recent Pongo data show, with 13 out of 17 adult individuals who suffered up to 5 stress events during that time. In fossil Pongo, results show that 2 out of 3 individuals at Duoi U'Oi, and 2 out of 6 individuals at Tham Khuyen suffered up to 3 stresses. During this period, a great number of tooth types form concomitantly, and defects are found either in the whole imbricational zone of crowns 
(I1/i1, P4/p4, M2/m2), or in a portion of the imbricational zone (12/i2, P3), that could explain in part high hypoplastic rates. Some teeth also have the higher hypoplastic susceptibility: I1/i1 (44.1 - 50 \%), I2/i2 (37.5 - 63 \%), P3/p3 (47.2 - $62.7 \%)$, P4/p4 (34.4 - 35.7 \%), M2/m2 (9.6 - $19.3 \%$ ) (Hannibal and Guatelli-Steinberg, 2005), and between 56.2 to $93.7 \%$ in our reference Pongo sample (Table 5SI). Yet, important changes in the behavior of infants also characterize this period and could provide further explanation for why they react more intensively to stressors. Although still largely dependent on their mothers (for nutrition, protection, warmth, etc.), they begin to explore their immediate environment (less than 10 meters away), acquire locomotor skills, become able to process food items, and learn to build nests (van Noordwijk et al., 2009). This acquisition of foraging independence is also highly correlated with the onset of the weaning process (Delgado and van Schaik, 2000), with all subsequent psychological and physiological consequences on the health status of individuals (Skinner et al., 2012). The etiology of LEH defects for this period is however impossible to reveal since it can be linked to multiple causes: diseases due to the virulence of parasites and other pathogens while infants are not yet resistant, malnutrition due to difficulties in processing food or fluctuations in fruit availability, psychologically stressful situations linked to first rejections by the mother, interaction with the other members of the group, or possible first encounters with arboreal predators, such as clouded leopards or pythons (Rijksen, 1978).

The $\sim 4-8$ years period shows lower LEH frequencies in the recent Pongo sample with 8 out of 17 adult individuals who suffered up to 3 stress events. At Duoi U'Oi, one individual suffered one stress event and, at Tham Khuyen, the 4 individuals suffered up to 2 stress events. The period coincides with the end of the crown formation of some teeth, 12/i2, p3 (only distal thirds of crowns), and with the crown formation of $\mathrm{M} 3 / \mathrm{m} 3$, also less susceptible to record LEH episodes (15.3 - 36.1 \%; Hannibal and Guatelli-Steinberg, 2005; 56.2 \% in our reference Pongo sample, Table 5SI). That transition phase corresponds to the progressive learning of independence for young individuals who then explore their environment far from their mothers (>50 m) (van Noordwijk et al., 2009), and progression towards complete weaning.

In recent orangutans, weaning is a long and gradual process, the aspects of which, social, nutritional and psychological, are difficult to describe by observers in the wild. In a Sumatran population, van Noordwijk and van Schaik (2005) observed that mothers began to reject suckling visits of the youngest infant around 5 years old, while the last observed suckling visit was that of a 7-year-old individual. The complete weaning age was estimated by these authors at around 8 years. However, it seems to occur earlier, around 5 - 6 years old, in some individuals of Bornean populations (van Noordwijk et al., 2009). The interbirth interval also provides data on the age of juveniles at the time of weaning, a new pregnancy occurring when they are completely weaned (but see Smith et al., 2017). Based on data compiled by Wish et al. (2009; Table 5.1) and by Knott et al. (2009; Table 11.1), mean intervals evaluated in two females of a Sumatran population (8.2 - 9.3 years) also appear significantly longer than those evaluated in three females of a Bornean population (6.1 - 7.7 years).

In relation to wild Sumatran populations, this ecological background of a late weaning has been be related to the high-quality of the food available, with more fruit and insects (vs more bark, unripe fruit and seeds in the diet of Bornean populations), and to fewer fluctuations in fruit availability over time (Galdikas and Wood, 1990; Delgado and van Schaik, 2000; Jablonski et al., 2000; Wich et al., 2004, 2006, 2009; van Noordwijk and van Schaik, 2005; Knott et al., 2009). 
The location of the most pronounced LEH defects on canine crowns in our recent Pongo sample corresponds to stress events which occurred in this $4.8-7.2$ years interval (four males), or earlier $\sim 3.4-4.7$ years (one female). Such morphology of enamel hypoplasia (in contrast with the morphology of adjacent lines within the same tooth), suggests a greater intensity of the stressor, or the interaction of two or more factors (Goodman and Rose, 1990). That might be consistent with the long dietary and behavioral transition of the weaning, known to be one of the most stressful periods in various large-bodied mammals (Mead, 1999; Dobney and Ervynck, 2000; Franz-Odendaal, 2003; Franz-Odendaal et al., 2004; Niven et al., 2004; Witzel et al., 2006).

The depression-type defect observed in one male individual (TK138; Table 13) from Tham Khuyen might correspond to the duration of weaning, estimated to have lasted around 2.5 years ( $4.8-7.5$ years old). For Witzel et al. (2006), this type of defect reflects a prolonged period of undernutrition. The most accentuated episodes recorded in two other male individuals (TK46, TK118; Table 13) between $\sim 6.5$ and 8 years, also suggest stressful events during the weaning period.

\subsection{Paleoecology of large-bodied mammals}

The Coc Muoi data indicated that rhinoceroses and wild cattle were exposed to multiple physiological and psychological stress events specific to age, at around birth (rhinoceros), weaning (wild cattle, orangutans), abandonment of calf (rhinoceros), or when juveniles reached sexual maturity (both groups).

The Coc Muoi fauna gives a good representation of a tropical megaherbivore-bearing ecosystem that occurred in this region of Southeast Asia, in the late Middle Pleistocene, during the MIS6 - 5, considering the time frame for breccia deposition between 148 and 117 ka (Bacon et al., 2018a). During the temperate MIS 6 phase, the climate remained particularly warm and wet at these latitudes. The age interval also includes the Eemian episode (5e: 124 - $119 \mathrm{ka}$ ), which was marked by the strengthening of the East Asian summer monsoon (Li et al., 2017; Wang et al., 2008). Under its influence, the climate was particularly warm and humid with most likely a great variation in seasonal rainfalls (Yuan et al., 2004; Ao et al. 2012). The climatic factors of temperature and humidity, which generate damp and flooded soils, are considered to be the most important environmental factors influencing the proliferation and virulence of parasites, which are sources of diseases for immature largebodied mammals (Skinner and Hopwood, 2004; Foitová et al., 2009).

In terms of paleoecology, Pleistocene orangutans from the Asian mainland could survive in different environmental conditions than those they occupy today, in nonanalog mammalian communities (Stewart, 2009). They occupied dense forests (Bocherens et al., 2017; Bacon et al., 2018b). Considering the location of fossiliferous deposits and the geological context of the area in northern Vietnam (Duringer et al., 2012), it is highly plausible that they lived in the limestone forests on hills and tower karsts. Today, limestone karst forests are inhabited by wild populations of low density, due to relatively low tree species diversity and limited productivity (vs forested habitats such as peat-swamp forests, lowland Dipterocarp forests or dry forests) (Marshall et al., 2007; Husson et al., 2009).

Body weight estimates made on the only complete skeleton of a female Pongo to be found in the mainland (with a range of 81.6 - $89.3 \mathrm{~kg}$ based on the crown areas of $\mathrm{M1} / \mathrm{m} 1$, and 58.8 - $83.1 \mathrm{~kg}$ based on long bones; Bacon and Vu The Long, 2003), support a greater body size in the fossil species compared to the body size of females in extant populations (Eckhart, 1975; Markham and Groves, 1990; Smith and Jungers, 1997). Considering the 
influence of body mass on life-histories in large mammals (Owen-Smith, 1988; GuadelliSteinberg et al., 2000; Jablonski et al., 2000), and the different ecological constraints due to past climatic conditions, the issue will be whether Pleistocene Pongo exhibited a different pattern of growth and development in comparison with extant orangutan populations.

\section{Conclusion}

In this study, we explored the prevalence and expression (furrow vs line of pits) of linear enamel hypoplasia (LEH) in Pongo from the Middle Pleistocene (Tham Khuyen, Coc Muoi) and the Late Pleistocene (Duoi U'Oi) karstic sites in northern Vietnam.

The results show that the LEH analysis based on isolated teeth is constrained by numerous biases including: the number of teeth; the differential representation of tooth types; the difficulty in distinguishing first from second molars; the small number of individuals [MNI]; the differential representation of males versus females within each Pongo sample.

The results indicate, nevertheless, that Pleistocene Pongo individuals experienced multiple LEH episodes over their long period of growth and development, with the two Coc Muoi individuals affected $(\mathrm{MNI}=2), 2$ out of 3 individuals at Duoi $\mathrm{U}^{\prime} \mathrm{Oi}(\mathrm{MNI}=3)$, and 4 out of 6 individuals at Tham Khuyen $(\mathrm{MNI}=6)$. They had a comparable pattern of defects to those of their modern counterparts, most likely linked to the same causes (undernutrition, disease). Further analyses on larger samples from Southeast Asian sites will allow for a better understanding of the evolution of ecological variables in the Pongo lineage.

\section{Acknowledgments}

We thank all members of the Institute of Archaeology in Hanoi, and particularly Ass. Prof. Nguyen Giang Hai, Director of the Institute, for the agreement to study the Duoi and Tham Khuyen collections. We thank also Mr. Nong Duc Kien, present Director of the Lang Son Museum, and Mr. Nguyen Gia Quyen and the other members of the Lang Son museum, regarding the study of the Coc Muoi collection.

Our thanks also go to Christine Lefèvre, Joséphine Lesur and Aurélie Verguin of the Laboratoire Mammifères et Oiseaux, Anatomie comparée, Muséum national d'Histoire naturelle, in Paris, for agreement and access to the Pongo collection ; Clément Zanolli, laboratoire PACEA, UMR 5199, Université de Bordeaux, for his helpful comments, Amandine Blin, Muséum national d'Histoire naturelle, Centre national de la Recherche scientifique, UMS 2700 2AD, in Paris, for her advice on possible statistical tests; Vincent Zvénigorosky for editing the text in English, and Professor Nguyen Lan Cuong from the Insitute of Archaeology in Hanoi, for his kind help to take photos of teeth of the Tham Khuyen collection. Finally, the authors thank the anonymous reviewers for their helpful critiques and suggestions. 


\section{References}

Anemone, R.L., Watts, E.S., Swindler, D.R., 1991. Dental development of known-age chimpanzees, Pan troglodytes (Primates, Pongidae). Am. J. Phys. Anthropol. 86, 229-241.

Ao, H., Dekkers, M.J., Xiao, G., Yang, X., Qin, L., Liu, X., Qiang, X., Chang, H., Zhao, H., 2012. Different orbital rythms in the Asian summer monsoon records from the North and South China during the Pleistocene. Glob. Planet. Change 80, 51-60.

Bacon A.-M., Vu The Long, 2003. L'orang-outan de Hoà Binh (Viêt-Nam) : poids corporel et hypothèse locomotrice. C. R. Palevol 2, 251-259.

Bacon A.-M., Demeter F., Duringer P., Helm C., Bano M., Vu The Long, Nguyen Kim Thuy, Antoine P.-O, Bui Thi Mai, Nguyen Thi Mai Huong, Dodo Y., Chabaux F., Rihs S., 2008. The Late Pleistocene Duoi U'Oi cave in northern Vietnam: palaeontology, sedimentology, taphonomy, palaeoenvironments. Quat. Sci. Rev. 27, 1627-1654.

Bacon A.-M., Westaway K., Antoine P.-O., Duringer P., Blin A., Demeter F., Ponche JL., Zhao JX., Barnes L., Sayavongkhamdy T., Nguyen Thi Kim Thuy, Patole-Edoumba E., Vu The Long, Shackelford L., 2015. Late Pleistocene mammalian assemblages of Southeast Asia: new dating, mortality profiles and evolution of the predator-prey relationships in an environmental context. Palaeogeogr. Palaeoclimatol. Palaeoecol. 422, 101-127.

Bacon A.-M., Antoine P.-O., Nguyen Thi Mai Huong, Westaway K., Nguyen Anh Tuan, Duringer P., Zhao Jx., Ponche JL., Sam Canh Dung, Truong Huu Nghia, Tran Thi Minh, Pham Tranh Son, Boyon M., Nguyen Thi Kim Thuy, Blin A., Demeter F., 2018a. A rhinocerotiddominated megafauna at the MIS6-5 transition: The late Middle Pleistocene Coc Muoi assemblage, Lang Son province, Vietnam. Quat. Sci. Rev. 186, 123-141.

Bacon A.-M., Bourgon N., Dufour E., Zanolli C., Duringer P., Ponche JL., Antoine P.-O., Shackelford L., Nguyen Thi Mai Huong, Sayavonkhamdy T., Patole-Edoumba E., Demeter F., 2018b. Nam Lot (MIS 5) and Duoi U'Oi (MIS 4) Southeast Asian sites revisited: Zooarchaeological and isotopic evidences. Palaeogeogr. Palaeoclimatol. Palaeoecol. 512, 132-144.

Beynon, A.D., Dean, M.C., Reid, D.J., 1991. Histological study on the chronology of the developing dentition in gorilla and orangutan. Am. J. Phys. Anthropol. 86, 189-203.

Bocherens, H., Schrenk, F., Chaimanee, Y., Kullmer, O., Mörike, D., Pushkina, D., Jaeger, J.-J., 2017. Flexibility of diet and habitat in Pleistocene South Asian mammals: Implications for the fate of the giant fossil ape Gigantopithecus. Quat. Int. 434, 148-155.

Brandon-Jones, D., Eudey, A.A., Geissmann, T., Groves, C.P., Melnick, D.J., Morales, J.C., Shekelle, M., Stewart, C.-B., 2004. Asian primate classification. Int. J. Primatol. 25, 97-164.

Ciochon, R.L., Long, V.T., Larick, R., Gonzalez, L., Grün, R., de Vos, J., Yonge, C., Taylor, L., Yoshida, H., Reagan, M., 1996. Dated co-occurrence of Homo erectus and Gigantopithecus from Tham Khuyen Cave, Vietnam. Proc. Natl. Acad. Sci. USA 93, 3016-3020.

Cuong, Nguyen Lan, 1985. Fossile Menschenfunde aus Nordvietnam, in: Herrmann, J., Ullrich, H . (Eds.), Menschwerdung - Biotischer und gesellschaftlicher Entwicklungsprozess. Berlin, Akademieverlag, pp. 96-102.

Dean, M.C., 2010. Retrieving chronological age from dental remains of early fossil hominins to reconstruct human growth in the past. Phil. Trans. Royal Soc. B. 365, 3397-3410.

Dean, M.C., Wood, B.A., 1981. Developing pongid dentition and its use for ageing individual crania in comparative cross-sectional growth studies. Folia primatol. 36, 111-127.

Dean, M.C., Beynon, A.D., 1991. Tooth crown heights, tooth wear, sexual dimorphism and jaw growth in hominoids. Z. Morphol. Anthropol. 78, 425-440. 
Dean, M.C., Beynon, A.D., Reid, D.J., Whittaker, D.K., 1993. A longitudinal study of tooth growth in a single individual based on long- and short-period incremental markings in dentine and enamel. Int. J. Osteoarchaeol. 3, 249-264.

Delgado, R.A., van Schaik, C.P., 2000. The Behavioral Ecology and Conservation of the Orangutan (Pongo pygmaeus): A Tale of Two Islands. Evol. Anthropol., 201-217.

Dirks, W., Reid, D.J., Jolly, C.J., Phillips-Conroy, J.E., Brett, F.L., 2002. Out of the mouths of baboons: stress, life history, and dental development in the Awash National Park hybrid zone, Ethiopia. Am. J. Phys. Anthropol. 118, 239-252.

Dirks, W., Humphrey, L.T., Dean, C.M., Jeffries, T.E., 2010. The relationships of accentuated lines in enamel to weaning stress in juvenile baboons (Papio hamadryas anubis). Folia primatol. 81, 207-223.

Dobney, K., Ervynck, A., 1998. A protocol for recording linear enamel hypoplasia on archaeological pig teeth. Int. J. Osteoarchaeol. 8, 263-273.

Dobney, K., Ervynck, A., 2000. Interpreting developmental stress in archaeological pigs: the chronology of linear enamel hypoplasia. J. Archaeol. Sci. 27, 597-607.

Duringer, P., Bacon, A.-M., Sayavongkhamdy, T., Nguyen Thi Kim Thuy, 2012. Karst development, breccias history, and mammalian assemblages in Southeast Asia: A brief review. C. R. Palevol 11, 133-157.

Eckhardt, R.B., 1975. The relative body weights of Bornean and Sumatran orangutans. Am. J. Phys. Anthropol. 42, 349-350.

Eckhardt, R.B., 1992. Tooth crown development: non-human primate perspectives on the interpretation of linear enamel hypoplasia frequencies in present and past hominid populations, in: Goodman, A.H., Capasso, L.L. (Eds.). Recent contributions to the study of enamel developmental defects. J. Paleopathol. Monogr. Ser 2, Chieti, Italy: Associazione Anthropologica Abruzzese, pp. 293-305.

Foitová, I., Huffman, M.A., Wisnu, N., Olšanský, 2009. Parasites and their impacts on orangutan health, in: Wich, S.A., Utami Atmoko, S.S., Mitra Setia T., \& van Schaik, C.P. (Eds.), In Orangutans. Geographic variation in behavioral ecology and conservation. Oxford University Press, pp. 157-169.

Francis, C.M., 2008. A field guide to the mammals of South-East Asia. New Holland Publishers, London.

Franz-Odendaal, T.A., Lee-Thorp, J.A., Chinsamy, A.A., 2003. Insights from stable light isotopes on enamel defects and weaning in Pliocene herbivores. J. Biosci. 28, 765-773.

Franz-Odendaal, T., 2004. Enamel hypoplasia provides insights into the early systemic stress in wild and captive giraffes (Giraffa cameloparalis). J. Zool. London, 263, 197-206.

Galdikas, B.M.F., Woods, J.W., 1990. Birth spacing pattern in human and apes. Am. J. Phys. Anthropol. 83, 185-191.

Goddard, J., 1970. Age criteria and vital statistics of a black rhinoceros population. E. Afr. Wild. J. 8, 105-121.

Goodman, A.H., Rose, J.C., 1990. Assessment of systemic physiological perturbations from dental enamel hypoplasias and associated histological structures. Yearb. Phys. Anthropol. 33, 59-110.

Goodman, A.H., Armelagos, G.J., 1985. Factors affecting the distribution of enamel hypoplasias within the human permanent dentition. Am. J. Phys. Anthropol. 68, 479-493.

Guatelli-Steinberg, D., 2000. Linear enamel hypoplasia in gibbons (Hylobates lar carpenteri). Am. J. Phys. Anthropol. 112, 395-410.

Guatelli-Steinberg, D., 2001. What can developmental defects of enamel reveal about physiological stress in nonhuman primates? Evol. Anthropol. 10, 138-151. 
Guatelli-Steinberg, D., Ferrell, R.J., Spence J., 2012. Linear enamel hypoplasia as an indicator of physiological stress in great apes: Reviewing the evidence in light of enamel growth variation. Am. J. Phys. Anthropol. 148, 191-204.

Hannibal, D.L., 2000. Linear enamel hypoplasia in the great apes: analysis of genus and locality. Am. J. Phys. Anthropol. 30 (suppl): 172.

Hannibal, D.L., Guatelli-Steinberg, D., 2005. Linear Enamel hypoplasia in the great apes: analysis by genus and locality. Am. J. Phys. Anthropol. 127, 13-25.

Harrison, T., Jin, C., Zhang, Y., Wang, Y., Zhu, M., 2014. Fossil Pongo from the Early Pleistocene Gigantopithecus fauna of Chongzuo, Guangxi, southern China. Quat. Int. 354, 59-67.

Hillman-Smith, A.K.K., Owen-Smith, N., Anderson, J. L., Hall-Martin, A. J., Selaladi, J. P., 1986. Age estimation of the white rhinoceros (Ceratotherium simum). J. Zool. 210, 355-377.

Hillson, S., 2005. Teeth. Cambridge Manuals in Archaeology, $2^{\text {nd }}$ Edition, Cambridge University Press.

Hillson, S., Bond, S., 1997. The relationship of enamel hypoplasia to the pattern of tooth crown growth: a discussion. Am. J. Phys. Anthropol. 104, 89-103.

Hürner, H., Vercauteren, M., 2003. Indicateurs de stress squelettiques et dentaires : qu'en est-il chez les grands singes africains ? Anthropologica et Praehistorica 114, 51-60.

Husson, S.J., Wich, S.A., Marshall, A.J., Dennis, R.D., Ancrenaz, M., Brassey, R., Gumal, M., Hearn, A.J., Meijaard, E., Simorangkir, T., Singleton, I., 2009. Orangutan distribution, density, abundance and impacts of disturbance, in: Wich, S.A., Utami Atmoko, S.S., Mitra Setia T., \& van Schaik, C.P. (Eds.), Orangutans. Geographic variation in behavioral ecology and conservation. Oxford University Press, pp. 77-96.

Jablonski, N.G., Whitfort, M.J., Roberts-Smith, N., Qinqi, X., 2000. The influence of life history and diet on the distribution of catarrhine primates during the Pleistocene in eastern Asia. J. Hum. Evol. 39, 131-157.

Kelley, J., 1995. Sexual dimorphism in canine shape among great apes. Am. J. Phys. Anthropol. 96, 365-389.

Kelley, J., Schwartz, G.T., 2010. Dental development and life history in living African and Asian apes. Proc. Natl. Acad. Sci. USA 107, 3, 1035-1040.

Knott, C.D., 1998. Changes in orangutan caloric intake, energy balance, and ketones in response to fluctuating fruit availability. Int. J. Primatol. 19, 1061-1079.

Knott, C., 2001. Female reproductive ecology of the apes: implications for human evolution, in: P.T. Ellison (Ed.), Reproductive ecology and human evolution. Walter de Gruyter, New York, pp. 429-463.

Knott, C.D., Emery Thompson, M., Wich, S.A., 2009. The ecology of female reproduction in wild orangutans, in: Wich, S.A., Utami Atmoko, S.S., Mitra Setia T., \& van Schaik, C.P. (Eds.), In Orangutans. Geographic variation in behavioral ecology and conservation. Oxford University Press, pp. 171-188.

Kuydendall, K.L., 1996. Dental development in chimpanzees (Pan troglodytes): The timing of tooth calcification stages. Am. J. Phys. Anthropol. 99, 135-157.

Li, D., Hu, C., Wang, W., Chen, J., Tian, F., Huang, S., Bae, C.J., 2017. The stable isotope record in cervid tooth enamel from Tantang cave, Guangxi: Implications for the Quaternary East Asian monsoon. Quat. Int. 434, 156-162.

Lovell, N. C., Whyte, I., 1999. Patterns of Dental Enamel Defects at Ancient Mendes, Egypt. American Journal of Physical Anthropology 110, 69-80.

Lukacs, J.R., 1999. Enamel hypoplasia in deciduous teeth of great apes: do differences in defect prevalence imply differential levels of stress? Am. J. Phys. Anthropol. 110, 351-363. 
Markham, R., Groves, C.P., 1990. Brief communication: Weights of wild orangutans. Am. J. Phys. Anthropol. 81, 1-3.

Marshall, A.J., Salas, L.A., Stephens, S., Nardiyono, Engström, L.M., Meijaard, E., Stanley, S., 2007. Use of limestone karst forests by Bornean orangutans (Pongo pygmaeus morio) in the Sangkulirang Peninsula, East Kalimantan, Indonesia. Am. J. Primatol. 69, 1-8.

McGrath, K., El-Zaatari, S., Guatelli-Steinberg, D., Stanton, M.A., Reid, D.J., Stoinski, T.S., Cranfield, M.R., Mudakikwa, A., McFarlin, S.C., 2018. Quantifying linear eamel hypoplasia in Viruga Mountain gorillas and other great apes. Am. J. Phys. Anthropol. 166, 337-352.

Mead, A.J., 1999. Enamel hypoplasia in Miocene rhinoceroses (Teleoceras) from Nebraska: Evidence of severe physiological stress. J. Vert. Paleontol. 19, 391-397.

Miles, A.E.W, Grigson, C., 2003. Colyer's variations and diseases of the teeth of animals. Revised Edition. Cambridge University Press, 672p.

Niven, L.B., Egeland, C.P., Todd, L.C., 2004. An inter-site comparison of enamel hypoplasia in bison: implications for paleoecology and modeling Late Plains Archaic subsistence. J. Archaeological Sci. 31, 1783-1794.

O'Hara, M., 2017. Applying standard perikymata profiles to Pongo pygmaeus canines to estimate perikymata counts between linear enamel hypoplasias. Am. J. Phys. Anthropol. $163,213-222$.

Owen-Smith, R.N., 1988. Megaherbivores. The influence of very large body size on ecology. Cambridge studies in ecology. Cambridge University Press.

Reid, D.J., Schwartz, G.T., Dean, M.C., Chandrasekera, M.S., 1998. A histological reconstruction of dental development in the common chimpanzee, Pan troglodytes. J. Hum. Evol. 35, 427-448.

Rijksen, H.D., 1978. A field study on Sumatran orang utans (Pongo pygmaeus abelii Lesson 1827): Ecology, behavior, and conservation. H. Veenman and Zonen B.V., Wageningen, The Netherlands.

Schwartz, G.T., Dean, C., 2001. Ontogeny of canine dimorphism in extant hominoids. Am. J. Phys. Anthropol. 115, 269-283.

Schwartz, J.H., Long, V.T., Cuong, N.L., Kha, L.T., Tattersall, I., 1994. A diverse hominoid fauna from the late Middle Pleistocene breccia cave of Tham Kuyen, Socialist Republic of Vietnam. Anthrop. Pap. Am. Mus. Nat. Hist. 74, 1-11.

Schwartz, J.H., Long, V.T., Cuong, N.L., Kha, L.T., Tattersall, I., 1995. A review of the Pleistocene hominoid fauna of the Socialist Republic of Vietnam. Anthrop. Pap. Am. Mus. Nat. Hist. 76, 1-24.

Skinner, M.F., 1986a. Enamel hypoplasia in sympatric chimpanzee and gorilla. Hum. Evol. 1, 289-312.

Skinner, M.F., 1986b. An enigmatic hypoplastic defect of the deciduous canine. Am. J. Phys. Anthropol. 69, 59-69.

Skinner, M.F., 2000. Periodicity of repetitive linear enamel hypoplasia in Asian and African apes. Am. J. Phys. Anthropol. [Suppl] 30, 283.

Skinner, M.F., Newell, E.A., 2003. Localized hypoplasia of the primary canine in bonobos, orangutans and gibbons. Am. J. Phys. Anthropol. 120, 61-72.

Skinner, M.F., Hopwood, D., 2004. Hypothesis for the causes and periodicity of repetitive linear enamel hypoplasia in large, wild African (Pan troglodytes and Gorilla gorilla) and Asian (Pongo pygmaeus) Apes. Am. J. Phys. Anthropol. 123, 216-235.

Skinner, M.F., Skinner, M.M., Boesch, C., 2012. Developmental defects of the dental crown in chimpanzees from the Taï National Park, Côte d'Ivoire: Coronal waisting. Am. J. Phys.

Anthropol. 149, 272-282. 
Skinner, M.F., Skinner, M.M., 2017. Orangutans, enamel defects, and developmental health: A comparison of Borneo and Sumatra. Am. J. Primatol. 79, e22668.

Smith, R.J., Jungers, W.L., 1997. Body mass in comparative primatology. J. Hum. Evol. 32, 523-559.

Smith, T.M., 2016. Dental development in living and fossil orangutans. J. Hum. Evol. 94, 92105.

Smith, T.M., Austin, C., Hinde, K., Vogel, E.R., Arora, M., 2017. Cyclical nursing patterns in wild orangutans. Science Advances 3, e1601517

Stottlemire, M.M., 1998. Presence of enamel hypoplasia in wild-shot chimpanzees (genus Pan) and gorillas (genus Gorilla). Am. J. Phys. Anthropol. 26, 212.

Stewart, J.R., 2009. The evolutionary consequence of the individualistic response to climate change. J. Evol. Biol. 22, 2363-2375.

Swindler, D.R., 1985. Primate dentition: an introduction to the teeth of non-human primates. Cambridge: Cambridge University Press.

Tafforeau, P., Bentaleb, I., Jaeger, J.J., Martin, C., 2007. Nature of laminations and mineralization in rhinoceros enamel using histology and $\mathrm{X}$-ray synchrotron microtomography: potential implications for palaeoenvironmental isotopic studies. Palaeogeogr. Palaeoclimatol. Palaeoecol. 246, 206-227.

Van Adrichem, G.J., Utami, S.S., Wich, S.A., van Hooff Jaram, Sterck, E.H.M., 2006. The development of wild immature Sumatran orangutans (Pongo abelii) at Ketambe. Primates 47, 300-309.

van Noordwijk, M.A., van Schaik, C.P., 2005. Development of ecological competence in Sumatran orangutans. Am. J. Phys. Anthropol. 127, 79-94.

van Noordwijk, M.A., Sauren, S.E.B., Nuzuar, Abulani, A., Morrogh-Bernard, H.C., Utami Atmoko, S.S., van Schaik, C.P., 2009. Development of independence, in: Wich, S.A., Utami Atmoko, S.S., Mitra Setia T., \& van Schaik, C.P. (Eds.), Orangutans. Geographic variation in behavioral ecology and conservation. Oxford University Press, pp. 189-203.

Waddle, D.M., Martin, L.B., Stock, D.A., 1995. Sexing isolated hominoid canines with special reference to the Middle Miocene specimens from Pașalar, Turkey. J. Hum. Evol. 28, 385403.

Wang, Y., Cheng, H., Edwards, R.L., Kong, X., Shao, X., Chen, S., Wu, J., Jiang, X., Wang, X., An, Z., 2008. Millenial- and orbital-scale changes in the East Asian monsoon over the past 224,000 years. Nature 451, 1090-1093.

Wich, S.A., Buij, R., van Schaik, C.P., 2004. Determinants of orangutan density in the dryland forests of the Leuser Ecosystem. Primates 45, 177-182.

Wich, S.A., Utami Atmoko, S.S., Mitra Setia, T., Djojosudharmo, S., Geurts, M.L., 2006. Dietary and energetic responses of Pongo abelii to fruit availability fluctuations. Int. J. Primatol. 27, 1535-1550.

Wich, S.A., de Vries, H., Ancrenaz, M., Perkins, L., Shumaker, R.W., Suzuki, A., van Schaik, C.P., 2009. Orangutan life history variation, in: Wich, S.A., Utami Atmoko, S.S., Mitra Setia T., van Schaik, C.P. (Eds.), Orangutans. Geographic variation in behavioral ecology and conservation. Oxford University Press, pp. 65-76.

Winkler, L.A., Schwartz, J.H., Swindler, D.R., 1991. Aspects of dental development in the orangutan prior to the eruption of the permanent dentition. Am. J. Phys. Anthropol. 86, 255-272.

Winkler, L.A., Schwartz, J.H., Swindler, D.R., 1996. Development of the orangutan permanent dentition: assessing patterns and variation in tooth development. Am. J. Phys. Anthropol. 99, 205-220. 
Witzel, C., Kierdorf, U., Dobney, K., Ervynck, A., Vanpoucke, S., Kierdorf, H., 2006.

Reconstructing impairment of secretory ameloblast function in porcine teeth by analysis of morphological alterations in dental enamel. Journal of Anatomy, 209, 93-110.

Yuan, D., Cheng, H., Edwards, R.L., Dykoski, C.A., Kelly, M.J., Zhang, M., Qing, J., Lin, Y., Wang, Y., Wu, J., Dorale, J.A., An, Z., Cai, Y., 2004. Timing, duration, and transitions of the last interglacial Asian monsoon. Science 304, 575-578.

\section{Table caption}

Table 1: Number and percentage of the teeth of large-sized bovids and rhinocerotids in the Coc Muoi and Duoi U'Oi collections showing no hypoplasia and one to four LEH episodes. In contrast to linear hypoplasia, permanent hypoplasia stands for long-lasting defects, observable on the entire height of the crown.

Table 2: LEH in large ungulates from Coc Muoi and Duoi U'Oi. NIhyp, number of individuals with enamel hypoplasia; MNI, minimum number of individuals; Tooth type refers to the tooth used to calculate the MNI (the most frequent type of tooth, either right or left); Time range of crown formation (bovids, Niven et al., 2004; rhinocerotids, Hillman-Smith et al., 1986; Tafforeau et al., 2007). ${ }^{(1)}$ All $\mathrm{m} 3 \mathrm{~s}$ assigned to $R$. sondaicus; ${ }^{(2)}$ One right $\mathrm{m} 3$ and one left $\mathrm{m} 2$ assigned to $R$. sondaicus and $D$. sumatrensis, respectively. No deciduous bovid teeth from Coc Muoi display LEH defects. Data on mean body weight of animals are from Francis (2008): Bos sauveli ( 800 kg), Rhinoceros sondaicus ( $1750 \mathrm{~kg})$, Rhinoceros unicornis ( 2250 $\mathrm{kg})$, Dicerorhinus sumatrensis ( 950 kg).

Table 3: Composition of the three fossil Pongo collections, by tooth type, and position on jaws (upper vs lower).

Table 4: Reference Table based on the observations of the 17 skulls of recent Pongo (adult individuals). Location of LEH episodes on the crown surface of molars, incisors and premolars (occlusal third, middle third, and basal third). The three periods of deficiency are delimited using crown formation times of $\mathrm{M} 1 / \mathrm{m} 1$ ( $\sim$ birth - 3 years), $\mathrm{M} 2 / \mathrm{m} 2$ ( $2-5$ years), and M3/m3 ( $\sim-8$ years). ${ }^{*}$ not observed in the sample.

Table 5: Number and percentage of permanent teeth showing LEH episodes in the three fossil collections. ${ }^{(1)}$ Two M1; ${ }^{(2)}$ Three $\mathrm{m} 1$ and four $\mathrm{m} 2$.

Table 6: Number and percentage of individuals in the recent Pongo sample $(N=17)$, and number and percentage of teeth in the fossil collections, showing 0 to 5 LEH episodes on incisors, premolars, and molars.

Table 7: Number of LEH episodes in recent Pongo individuals ( $N=17$ ) using incisors, premolars and molars, by period of development based on crown formation times of $\mathrm{M} 1 / \mathrm{m} 1$ ( birth - 3 years), M2/m2 ( 2 - 5 years), and M3/m3 ( $4-8$ years). See Tables $3 S$ I for the location of defects on teeth. Data indicate a great variability (1 out of 17 individuals shows no LEH episode; 8 out of 17 show LEH episodes only in the 2 - 5 years interval; 3 out of 17 only in the $\sim 4$ - 8 years interval; 4 out of 17 individuals in the $\sim 2-8$ years interval; and 1 out of 17 from birth to 8 years of age). The catalog number of skulls is noted in the second row of the Table. 
Table 8: Number (range and mean) of LEH episodes by period in males, females, and all recent Pongo individuals. Only individuals showing at least one episode have been considered $(N=16)$. $n$, number of affected individuals; $N$, number of individuals per group.

Table 9: Number of LEH episodes (range) on incisors (I1/1, I2/i2), premolars (P3/p3, P4/p4), and molars (M3/m3) in the fossil Pongo samples. $n$, number of individuals; $N$, number of individuals per group (see Table 4SI). The distinction between first and second molars ( $\mathrm{M} 1 / \mathrm{m} 1$ and $\mathrm{M} 2 / \mathrm{m} 2$ ) using only external morphology is often impossible (close morphology, presence of two facets of contact), whereas the distinction of $\mathrm{M} 3 / \mathrm{m} 3$ from the two first molars is possible (morphology of the hypoconulid on $\mathrm{m} 3$ and absence of a facet of contact on the distal side of the crown on $\mathrm{M} 3 / \mathrm{m} 3$ ). Figure in brackets refers to the number of teeth.

Table 10: Number of LEH episodes (range) on all fossil Pongo teeth. The period $\sim 0-5$ years allows for gathering all incisors, premolars and $\mathrm{M} 1-2 / \mathrm{m} 1-2$ in a single subsample. $\mathrm{n}$, number of individuals; $N$, number of individuals per group. Figure in brackets refers to the number of teeth.

Table 11: Number and percentage of individuals showing different types of defects (either furrow or line of pits, or both) by tooth type, in the recent Pongo sample. n, number of individuals; $\mathrm{N}$, number of individuals per group. We consider the individuals showing at least one LEH episode $(N=16)$. See Table 5 SI for details.

Table 12: MNI, sex of individuals, and number of LEH episodes (range, mean, and median) on lower canines of Tham Khuyen, and canines of two recent Pongo samples (our reference sample with 3 upper and 4 lower canines; and another sample of lower canines from Guatelli-Steinberg et al. (2012). Data from Guatelli-Steinberg et al. (2012) are based on the scoring of accentuated lines or grooves under $20 x$ magnification. $m$, male; $f$, female.

Table 13: Number of LEH episodes over the crown height (N), type (furrow vs line of pits) and location (distance from the cervix, standardized against crown height) of the most accentuated LEH episode visible on lower and ${ }^{(*)}$ upper canines of nine individuals of our recent Pongo sample, and seven canines from Tham Khuyen ( $\mathrm{MNI}=4$; three males and one female; TK138 and TK157 could belong to a single individual). Age ranges are based on age estimates of canine crown deciles from Skinner and Skinner (2017; Figure 5).

\section{Figure caption}

Figure 1: Photos of permanent teeth of recent Pongo skulls showing the two morphologies (arrows) used in the paper for scoring LEH: A pit-form defect displays either small and shallow pits (A), or deep pits located in a marked groove (B); A furrow-form defect displays either a faint groove (C), or a deep groove (D).

Figure 2: Photos of skulls of recent Pongo showing different types of LEH. We considered only the lines and furrows that can be matched on teeth forming at the same time. A. Young male adult mandible (1872-547) with one LEH episode; B. Male adult mandible (1927-98) with multiple LEH episodes on incisors, canines, and premolars (deep furrows and troughs are visible on lower p3 and p4 crowns); C. Young adult of unknown sex (AC1990) showing both lines of pits and furrows on upper incisors; D. Young female adult maxilla (A10683) showing faint furrows on crowns of upper premolars and molars (lingual view). Collections 
Mammifères et Oiseaux, Anatomie comparée of the Muséum national d'Histoire naturelle, Paris.

Figure 3: Photos of three lower canines from the Tham Khuyen collection: A: TK118; B: TK46; C: TK138. The arrows indicate the location of the most accentuated LEH marks (A, B), or a possible coronal waisting (C) (photos of Professor Nguyen Lan Cuong). 
Table 1

\begin{tabular}{|l|l|c|c|c|c|c|c|c|}
\hline & & no LEH & 1 LEH & 2 LEH & 3 LEH & 4 LEH & Permanent & Total \\
\hline \multirow{4}{*}{ Coc Muoi } & \multirow{2}{*}{ Rhinocerotid } & 193 & 30 & 20 & 10 & 1 & 10 & 264 \\
& & $73.1 \%$ & $11.3 \%$ & $7.5 \%$ & $3.7 \%$ & $0.3 \%$ & $3.7 \%$ & - \\
\cline { 2 - 9 } & \multirow{2}{*}{ Bovid } & 58 & 10 & 1 & - & - & - & 69 \\
& & $84 \%$ & $14.4 \%$ & $1.4 \%$ & - & - & - & - \\
\hline \multirow{2}{*}{ Duoi U'Oi } & \multirow{2}{*}{ Rhinocerotid } & 47 & 3 & 2 & - & - & - & 52 \\
& & $90.3 \%$ & $5.7 \%$ & $3.8 \%$ & - & - & - & - \\
\hline
\end{tabular}

Table 2

\begin{tabular}{|c|c|c|c|c|c|c|c|}
\hline & & $\begin{array}{c}\text { Range of body } \\
\text { weight }\end{array}$ & NIhyp/MNI & $\begin{array}{l}\text { Tooth } \\
\text { type }\end{array}$ & $\begin{array}{c}\text { Time range of crown } \\
\text { formation }\end{array}$ & $\begin{array}{l}\text { Period of } \\
\text { stress }\end{array}$ & $\begin{array}{c}\text { Biological and } \\
\text { behavioral events }\end{array}$ \\
\hline \multirow{4}{*}{ Coc Muoi } & \multirow[b]{2}{*}{ Rhinocerotid } & \multirow[b]{2}{*}{$\sim 950-2250 \mathrm{~kg}$} & $1 / 18$ & Id 4 & prenatal - 4 months & perinatal & birth \\
\hline & & & $10^{(1)} / 25$ & $\mathrm{rm} 3$ & $\sim 3-7$ years & $\sim 4-6$ years & $\begin{array}{c}\text { abandonment of calf } \\
\text { sexual maturity }\end{array}$ \\
\hline & \multirow{2}{*}{ Bovid } & \multirow{2}{*}{$\sim 800 \mathrm{~kg}$} & $3 / 13$ & $\operatorname{Im} 2$ & $\sim 2$ - 13 months & $\sim 9$ months & weaning \\
\hline & & & $3 / 6$ & $\mathrm{rm3}$ & $\sim 8$ - 24 months & $\sim 2$ years & sexual maturity \\
\hline \multirow[b]{2}{*}{ Duoi U'Oi } & \multirow[b]{2}{*}{ Rhinocerotid } & \multirow[b]{2}{*}{$\sim 950-2250 \mathrm{~kg}$} & $2 / 10$ & Id3 & prenatal - 15 months & perinatal & birth \\
\hline & & & $2^{(2)} / 7$ & $\mathrm{rm} 3$ & $\sim 3-7$ years & $\sim 4-6$ years & $\begin{array}{c}\text { abandonment of calf } \\
\text { sexual maturity }\end{array}$ \\
\hline
\end{tabular}

Table 3

\begin{tabular}{|c|c|c|c|c|c|c|c|c|c|c|c|c|c|c|c|}
\hline & & di1 & dc & I1 & I2 & I & C & P3 & P4 & M1/M2 & M1 & M2 & M3 & M & Total \\
\hline \multirow{2}{*}{ Coc Muoi } & Lower & - & - & 1 & - & - & - & 1 & 1 & 4 & - & - & 1 & - & \multirow{2}{*}{20} \\
& Upper & - & - & 1 & - & - & 1 & 1 & 2 & 5 & - & - & - & 2 & \\
\hline \multirow{2}{*}{ Duoi U'Oi } & Lower & - & 1 & 2 & 2 & - & - & 5 & 4 & 6 & - & - & 1 & - & \multirow{2}{*}{32} \\
& Upper & 1 & - & - & - & & 1 & 2 & 2 & 3 & 2 & - & - & - & \\
\hline \multirow{2}{*}{ Tham Khuyen } & Lower & - & - & 2 & 2 & 1 & 7 & - & 1 & 3 & 3 & 4 & 2 & - & \multirow{2}{*}{60} \\
& Upper & - & - & 1 & - & - & - & 6 & 4 & 16 & - & - & 8 & & \\
\hline
\end{tabular}


Table 4

\begin{tabular}{|c|c|c|}
\hline Period of deficiency & $\begin{array}{l}\text { Location of defects on } \\
\text { molars }\end{array}$ & $\begin{array}{l}\text { Location of corresponding defects on incisors and } \\
\text { premolars }\end{array}$ \\
\hline \multirow{3}{*}{ birth - 3 years } & $\mathrm{M} 1 / \mathrm{m} 1$ (occlusal)* & - \\
\hline & $\mathrm{M} 1 / \mathrm{m} 1$ (middle)* & I1/i1, I2/i2 (occlusal)* \\
\hline & $\mathrm{M} 1 / \mathrm{m} 1$ (basal) & I1/i1, I2/i2 (occlusal)* \\
\hline \multirow{3}{*}{$\sim 2-5$ years } & $\mathrm{M} 2 / \mathrm{m} 2$ (occlusal/middle) & I1/i1, I2/i2 (occlusal/middle), P3/p3, P4/p4 (occlusal/middle) \\
\hline & $\mathrm{M} 2 / \mathrm{m} 2$ (middle) & I1/i1, I2/i2 (middle), P3/p3, P4/p4 (middle) \\
\hline & $\mathrm{M} 2 / \mathrm{m} 2$ (middle/basal) & I1/i1, I2/i2 (basal), p3 (basal) \\
\hline \multirow{3}{*}{$\sim 4-8$ years } & M3/m3 (occlusal/middle) & 12/i2 (basal), p3 (basal) \\
\hline & $\mathrm{M} 3 / \mathrm{m} 3$ (middle) & p3 (basal) \\
\hline & M3/m3 (middle/basal) & - \\
\hline
\end{tabular}

Table 5

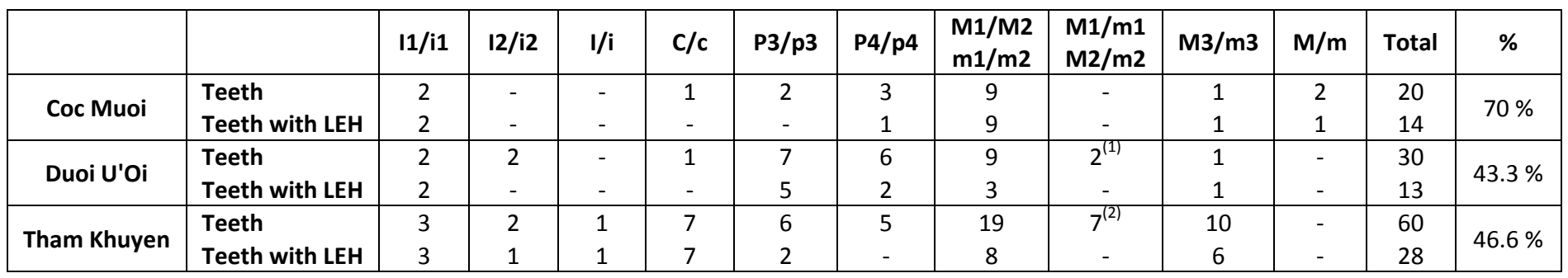

Table 6

\begin{tabular}{|c|c|c|c|c|c|c|c|c|c|c|c|c|c|}
\hline \multirow[b]{2}{*}{ Recent Pongo } & \multicolumn{2}{|c|}{ No LEH } & \multicolumn{2}{|c|}{$1 \mathrm{LEH}$} & \multicolumn{2}{|c|}{2 LEH } & \multicolumn{2}{|c|}{3 LEH } & \multicolumn{2}{|c|}{4 LEH } & \multicolumn{2}{|c|}{5 LEH } & \multirow{2}{*}{$\begin{array}{l}\text { Total } \\
\mathrm{N}=17\end{array}$} \\
\hline & 1 & $5.8 \%$ & 5 & $29.4 \%$ & 4 & $23.5 \%$ & 5 & $29.4 \%$ & 1 & $5.8 \%$ & 1 & $5.8 \%$ & \\
\hline Coc Muoi & 5 & $26.3 \%$ & 9 & $47.3 \%$ & 5 & $26.3 \%$ & - & - & - & - & - & - & $\mathrm{n}=19$ \\
\hline Duoi U'Oi & 16 & $55.1 \%$ & 8 & $27.5 \%$ & 4 & $13.7 \%$ & - & - & 1 & $3.4 \%$ & - & - & $n=29$ \\
\hline Tham Khuyen & 32 & $60.3 \%$ & 5 & $9.4 \%$ & 11 & $20.7 \%$ & 5 & $9.4 \%$ & - & - & - & - & $n=53$ \\
\hline
\end{tabular}


Table 7

\begin{tabular}{|c|c|c|c|c|c|c|c|c|c|c|c|c|c|c|c|c|c|}
\hline & \multicolumn{12}{|c|}{ Male } & \multicolumn{4}{|c|}{ Female } & \multirow{2}{*}{$\begin{array}{c}\text { unknown } \\
\text { 욜 } \\
\text { ํㅝㄴ }\end{array}$} \\
\hline & $\begin{array}{l}\text { Фે } \\
\text { ஸे } \\
\text { ๙ે }\end{array}$ & 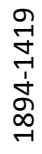 & 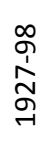 & 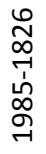 & 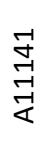 & \begin{tabular}{l}
0 \\
\multirow{L}{+}{} \\
$\stackrel{1}{N}$ \\
$\infty$ \\
$\sim$
\end{tabular} & 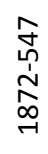 & 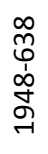 & 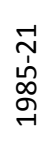 & 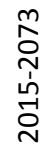 & 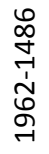 & 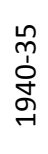 & 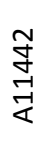 & $\begin{array}{l}m \\
\infty \\
0 \\
0 \\
\stackrel{1}{<} \\
\stackrel{1}{<}\end{array}$ & 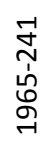 & 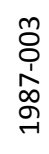 & \\
\hline birth -3 years & 0 & 0 & 0 & 0 & 0 & 0 & 0 & 0 & 0 & 0 & 0 & 0 & 0 & 0 & 0 & 1 & 0 \\
\hline$\sim 2-5$ years & 0 & 0 & 5 & 0 & 1 & 2 & 1 & 2 & 1 & 0 & 1 & 3 & 2 & 1 & 1 & 2 & 3 \\
\hline$\sim 4-8$ years & 3 & 2 & 0 & 1 & 0 & 1 & 0 & 1 & 0 & 0 & 1 & 0 & 0 & 1 & 0 & 1 & 0 \\
\hline Total & 3 & 2 & 5 & 1 & 1 & 3 & 1 & 3 & 1 & 0 & 2 & 3 & 2 & 2 & 1 & 4 & 3 \\
\hline
\end{tabular}

Table 8

\begin{tabular}{|c|c|c|c|c|c|c|c|c|c|}
\hline & \multicolumn{3}{|c|}{ Male } & \multicolumn{3}{|c|}{ Female } & \multicolumn{3}{|c|}{ All } \\
\hline & \multicolumn{2}{|c|}{ LEH episode } & \multirow{2}{*}{$\frac{\text { Individual }}{\mathrm{n} / \mathrm{N}}$} & \multicolumn{2}{|c|}{ LEH episode } & \multirow{2}{*}{$\frac{\text { Individual }}{\mathrm{n} / \mathrm{N}}$} & \multicolumn{2}{|c|}{ LEH episode } & \multirow{2}{*}{$\begin{array}{c}\text { Individual } \\
\mathrm{n} / \mathrm{N}\end{array}$} \\
\hline & range & mean & & range & mean & & range & mean & \\
\hline$\sim$ birth -3 years & - & - & - & - & 1 & $1 / 4$ & 1 & 1 & $1 / 16$ \\
\hline$\sim 2-5$ years & $1-5$ & 2 & $8 / 11$ & $1-2$ & 1.5 & $4 / 4$ & $1-5$ & 1.92 & $13 / 16$ \\
\hline$\sim 4-8$ years & $1-3$ & 1.5 & $6 / 11$ & 1 & 1 & $2 / 4$ & $1-3$ & 1.37 & $8 / 16$ \\
\hline
\end{tabular}

Table 9

\begin{tabular}{|l|c|c|c|c|c|c|}
\cline { 2 - 7 } \multicolumn{1}{c|}{} & \multicolumn{2}{c|}{ Coc Muoi } & \multicolumn{2}{c|}{ Duoi U'Oi } & \multicolumn{2}{c|}{ Tham Khuyen } \\
\cline { 2 - 7 } & $\begin{array}{c}\text { Range } \\
\text { (LEH episodes) }\end{array}$ & $\mathbf{n} / \mathbf{N}$ & $\begin{array}{c}\text { Range } \\
\text { (LEH episodes) }\end{array}$ & $\mathbf{n / N}$ & $\begin{array}{c}\text { Range } \\
\text { (LEH episodes) }\end{array}$ & $\mathrm{n} / \mathbf{N}$ \\
\hline$\sim$ birth -3 years & - & - & $1(1)$ & $1 / 2$ & - & - \\
\hline$\sim \mathbf{2}-\mathbf{5}$ years & $1-2(3)$ & $1 / 2$ & $1-3(9)$ & $2 / 2$ & $1-3(7)$ & $2 / 4$ \\
\hline$\sim \mathbf{4 - 8}$ years & $2(1)$ & $1 / 2$ & $1(1)$ & $1 / 2$ & $1-2(6)$ & $4 / 4$ \\
\hline
\end{tabular}

Table 10

\begin{tabular}{|l|c|c|c|c|c|c|}
\cline { 2 - 7 } \multicolumn{1}{c|}{} & \multicolumn{2}{c|}{ Coc Muoi } & \multicolumn{2}{c|}{ Duoi U'Oi } & \multicolumn{2}{c|}{ Tham Khuyen } \\
\cline { 2 - 7 } & $\begin{array}{c}\text { Range } \\
\text { (LEH episodes) }\end{array}$ & $\mathbf{n} / \mathbf{N}$ & $\begin{array}{c}\text { Range } \\
\text { (LEH episodes) }\end{array}$ & $\mathbf{n} / \mathbf{N}$ & $\begin{array}{c}\text { Range } \\
\text { (LEH episodes) }\end{array}$ & $\mathbf{n} / \mathbf{N}$ \\
\hline$\sim \mathbf{0 - 5}$ years & $1-2(12)$ & $2 / 2$ & $1-4(12)$ & $2 / 2$ & $1-3(15)$ & $3 / 4$ \\
\hline$\sim \mathbf{4 - 8}$ years & $2(1)$ & $1 / 2$ & $1(1)$ & $1 / 2$ & $1-2(6)$ & $4 / 4$ \\
\hline
\end{tabular}


Table 11

\begin{tabular}{|c|c|c|c|c|c|c|}
\hline & \multicolumn{2}{|c|}{ Furrow } & \multicolumn{2}{|c|}{ Line of pits } & \multicolumn{2}{|c|}{ Two types } \\
\hline & $n / N$ & $\%$ & $n / N$ & $\%$ & $n / N$ & $\%$ \\
\hline I1/i1 & $5 / 8$ & 62.5 & $2 / 8$ & 25 & $1 / 8$ & 12.5 \\
\hline 12/i2 & $6 / 9$ & 66.6 & $1 / 9$ & 11.1 & $2 / 9$ & 22.2 \\
\hline P3/p3 & $11 / 15$ & 73.3 & $2 / 15$ & 13.3 & $2 / 15$ & 13.3 \\
\hline P4/p4 & $5 / 9$ & 55.5 & $2 / 9$ & 22.2 & $2 / 9$ & 22.2 \\
\hline $\mathrm{M} 1 / \mathrm{m} 1$ & $1 / 1$ & 100 & - & - & - & - \\
\hline $\mathrm{M} 2 / \mathrm{m} 2$ & $8 / 12$ & 66.6 & $3 / 12$ & 25 & $1 / 12$ & 8.3 \\
\hline $\mathrm{M} 3 / \mathrm{m} 3$ & $7 / 9$ & 77.7 & $2 / 9$ & 22.2 & - & - \\
\hline
\end{tabular}

Table 12

\begin{tabular}{|c|c|c|c|c|c|c|c|}
\hline & & \multicolumn{2}{|c|}{ Individual } & \multicolumn{3}{|c|}{ LEH } & \\
\hline & & MNI & Sex & Range & Mean & Median & \\
\hline \multirow{2}{*}{ Pongo } & \multirow{2}{*}{ All canines } & 7 & $7 \mathrm{~m}$ & $1-9$ & 5.1 & 5 & \multirow{2}{*}{ This study } \\
\hline & & 2 & $2 f$ & $1-3$ & 2 & 2 & \\
\hline Pongo pygmaeus & Lower canines & 23 & $9 m, 13 f, 1 u$ & $2-10$ & 4.5 & 5 & \multirow{2}{*}{$\begin{array}{c}\text { Guatelli-Steinberg et } \\
\text { al., } 2012\end{array}$} \\
\hline Pongo abelii & Lower canines & 9 & $7 m, 2 f$ & $3-11$ & 7.4 & 7 & \\
\hline \multirow{2}{*}{ Tham Khuyen } & \multirow{2}{*}{ Lower canines } & 3 & $6 \mathrm{~m}$ & $3-10$ & 7.3 & 8 & \multirow{2}{*}{ This study } \\
\hline & & 1 & $1 f$ & 1 & 1 & 1 & \\
\hline Tham Khuyen & Lower canines & 4 & $6 m, 1 f$ & $1-10$ & 6.4 & 8 & This study \\
\hline
\end{tabular}


Table 13

\begin{tabular}{|c|c|c|c|c|c|c|}
\hline Origin & Catalog Number & Sex & $\mathbf{N}$ & $\begin{array}{c}\text { Type of the most } \\
\text { accentuated } \\
\text { episode }\end{array}$ & Location & $\begin{array}{l}\text { Age range } \\
\text { (years) }\end{array}$ \\
\hline- & $1985-1826$ & male* & 8 & \multicolumn{2}{|c|}{8 furrows of same expression } & - \\
\hline Borneo & $1894-1419$ & male* & 7 & \multicolumn{2}{|c|}{7 furrows of same expression } & - \\
\hline Borneo & $1872-547$ & male & 1 & 1 wide line of pits & $0.66-0.60$ & $3.21-3.99(4)$ \\
\hline- & $1948-638$ & male & 3 & 2 furrows & $0.31-0.23$ & $6.46-7.25(8)$ \\
\hline Borneo & $1872-546$ & male & 3 & 2 furrows & $0.45-0.31$ & $4.84-6.46(6-7)$ \\
\hline- & $1927-98$ & male & 9 & 1 wide line of pits & $0.33-0.25$ & $5.67-7.25(7-8)$ \\
\hline- & $1940-135$ & male & 5 & 2 furrows & $0.39-0.35$ & $5.67-6.46(7)$ \\
\hline- & 1987-003 & female & 3 & \multicolumn{2}{|c|}{3 furrows of same expression } & - \\
\hline- & $1965-241$ & female* & 1 & 1 wide furrow & $0.36-0.27$ & $3.45-4.77(7-8)$ \\
\hline Vietnam & TK 46 right & male & 8 & 2 lines of pits & $0.30-0.25$ & $6.46-7.25(8)$ \\
\hline Vietnam & TK 118 right & male & 8 & 2 lines of pits & $0.22-0.17$ & $6.46-8.09(8-9)$ \\
\hline Vietnam & TK 142A left & male & 3 & \multicolumn{2}{|c|}{ not clearly discernible } & - \\
\hline Vietnam & TK 138 right & male & 8 & \multicolumn{2}{|c|}{ Presence of coronal waisting? $(\sim 0.20-0.48)$} & $4.84-7.25(6-8)$ \\
\hline Vietnam & TK 157 left & male & 7 & \multicolumn{2}{|c|}{ Presence of coronal waisting? } & - \\
\hline Vietnam & TK 142 left & male & 10 & \multicolumn{2}{|c|}{ not clearly discernible } & - \\
\hline Vietnam & TK 143 left & female & 1 & \multicolumn{2}{|c|}{ not clearly discernible } & - \\
\hline
\end{tabular}


Figure 1

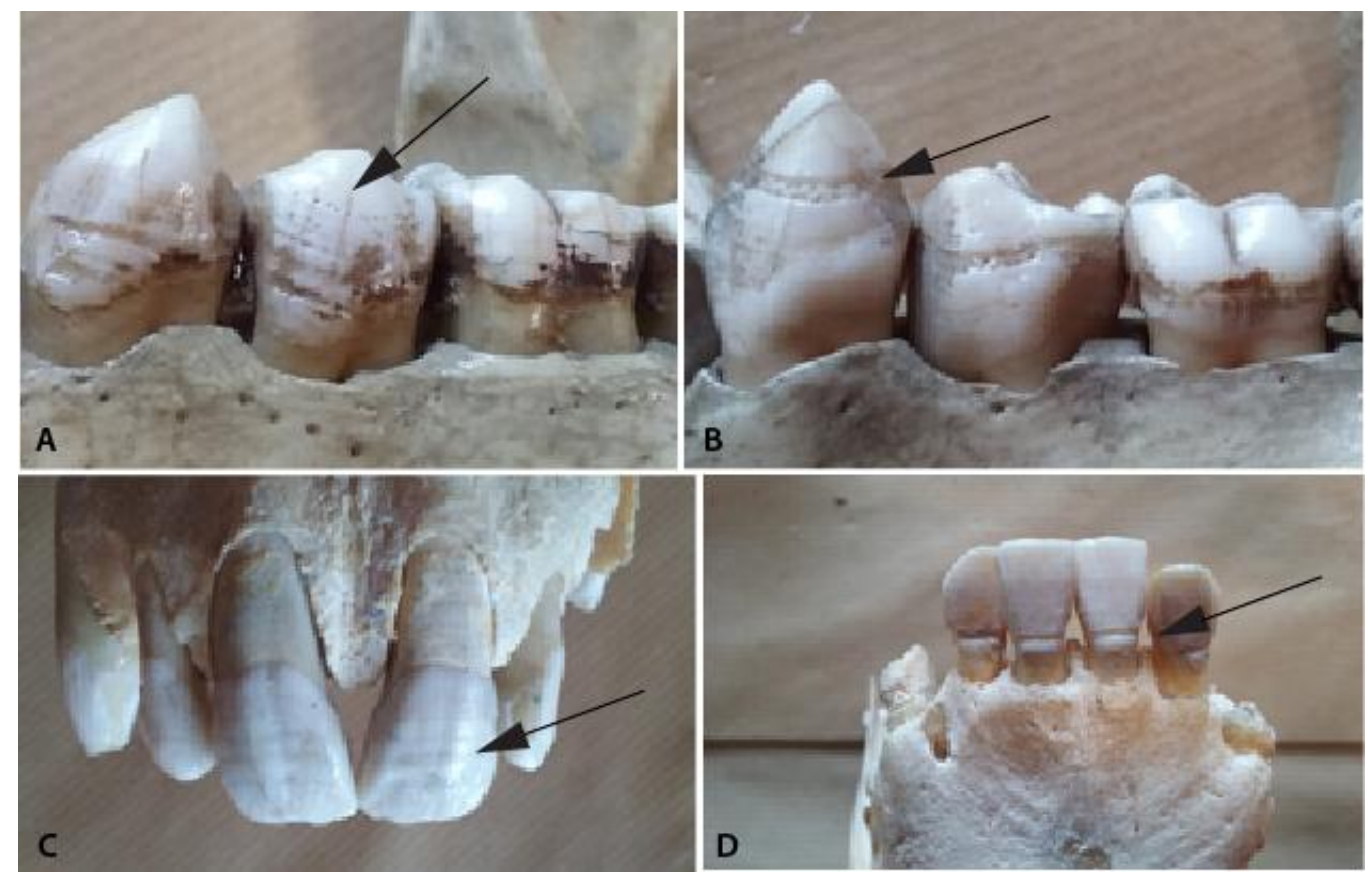

Figure 2

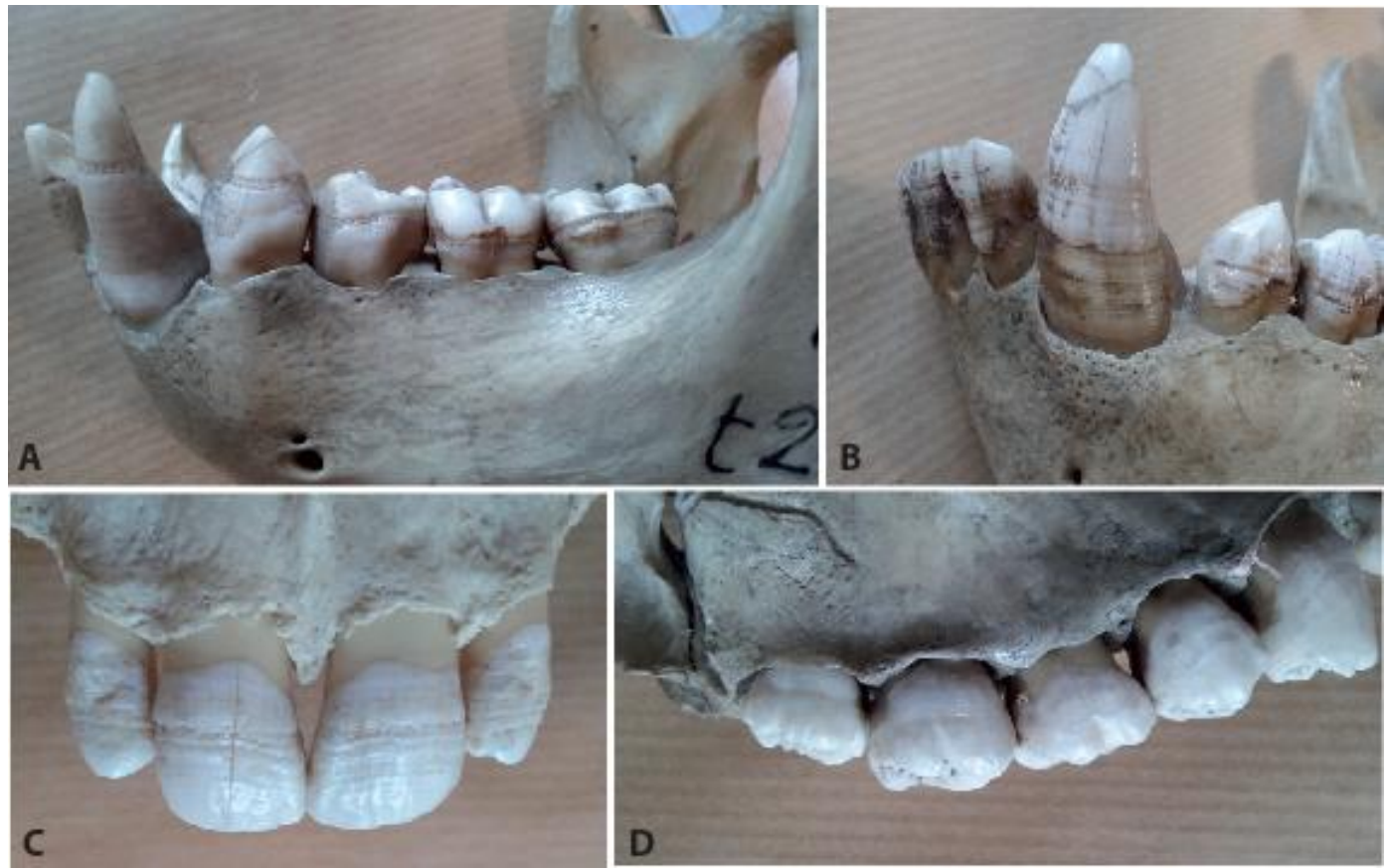


Figure 3
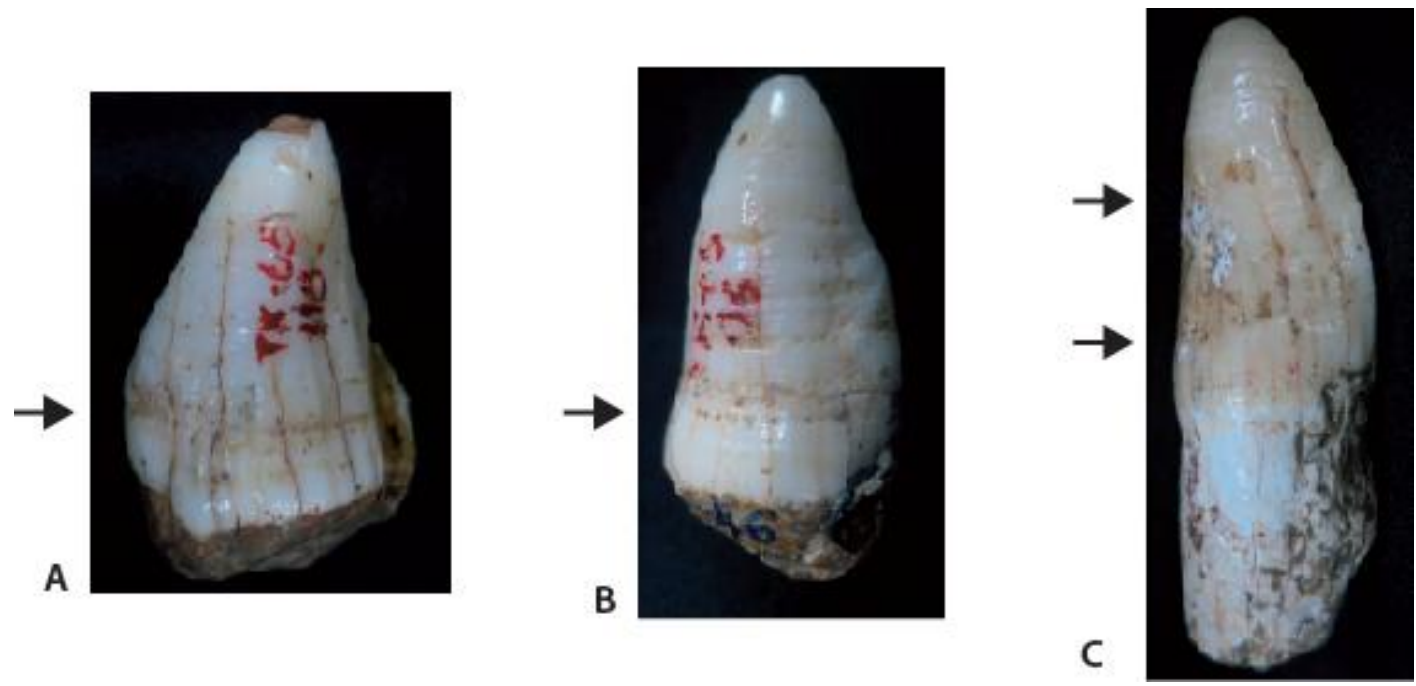